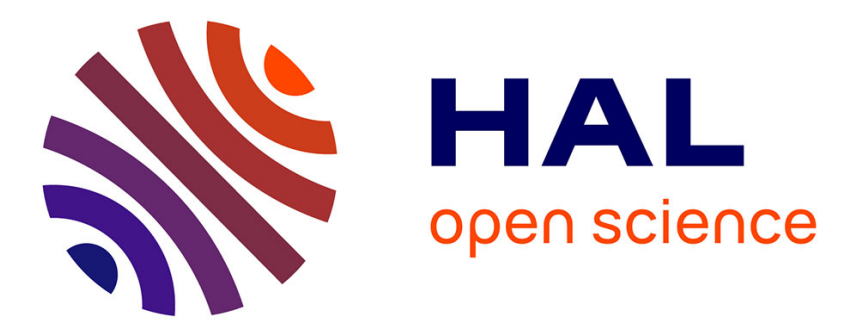

\title{
Highly stretchable hydrogels from complex coacervation of natural polyelectrolytes
}

\author{
Gautier Lalevée, Laurent David, Alexandra Montembault, Kevin Blanchard, \\ John Meadows, Sébastien Malaise, Agnès Crépet, Isabelle Grillo, Isabelle \\ Morfin, Thierry Delair, et al.
}

\section{To cite this version:}

Gautier Lalevée, Laurent David, Alexandra Montembault, Kevin Blanchard, John Meadows, et al.. Highly stretchable hydrogels from complex coacervation of natural polyelectrolytes. Soft Matter, 2017, 13 (37), pp.6594 - 6605. 10.1039/c7sm01215b . hal-01656308

\section{HAL Id: hal-01656308 https://hal.science/hal-01656308}

Submitted on 9 May 2019

HAL is a multi-disciplinary open access archive for the deposit and dissemination of scientific research documents, whether they are published or not. The documents may come from teaching and research institutions in France or abroad, or from public or private research centers.
L'archive ouverte pluridisciplinaire $\mathbf{H A L}$, est destinée au dépôt et à la diffusion de documents scientifiques de niveau recherche, publiés ou non, émanant des établissements d'enseignement et de recherche français ou étrangers, des laboratoires publics ou privés. 


\section{Highly Stretchable Hydrogels from Complex Coacervation}

\section{of Natural Polyelectrolytes}

Gautier Lalevée, ${ }^{\mathrm{a}, \mathrm{b}}$ Laurent David, ${ }^{\mathrm{a}}$ Alexandra Montembault, ${ }^{\mathrm{a}}$ Kevin Blanchard, ${ }^{\mathrm{a}}$ John Meadows, ${ }^{\mathrm{b}}$ Sébastien Malaise, ${ }^{b}$ Agnès Crépet, ${ }^{a}$ Isabelle Grillo, ${ }^{c}$ Isabelle Morfin, ${ }^{\mathrm{d}, \mathrm{e}}$ Thierry Delair, ${ }^{\mathrm{a}, *}$ and Guillaume Sudre ${ }^{\mathrm{a}, *}$

${ }^{a}$ Ingénierie des Matériaux Polymères (IMP), Univ Lyon, Université Claude Bernard Lyon 1, CNRS UMR 5223, 15 Boulevard Latarjet, F-69622, Villeurbanne, France

${ }^{b}$ Laboratoire ObvieLine, Sinclair IS Pharma, 8 chemin du Jubin, F-69570, Dardilly, France

${ }^{c}$ Institut Laue-Langevin, 71 Avenue des Martyrs, CS 20156, 38042 Grenoble Cedex 9, France

${ }^{d}$ LIPhy, University of Grenoble Alpes, F-38000 Grenoble, France,

${ }^{e}$ LIPhy, CNRS, F-38000 Grenoble, France

Published in Soft Matter:

Highly Stretchable Hydrogels from Complex Coacervation of Natural Polyelectrolytes. Lalevée G., David L., Montembault A., Blanchard K., Meadows J., Malaise S., Crépet A., Grillo I., Morfin I., Delair T., Sudre G., Soft Matter, 2017, 13(37), 6594-6605.

Link to the publisher version: http://dx.doi.org/10.1039/C7SM01215B

Creative Commons Attribution Non-Commercial No Derivatives License 


\begin{abstract}
The controlled complex coacervation of oppositely charged hyaluronic acid ( $M w \approx 800-1000$ $\left.\mathrm{kg} \cdot \mathrm{mol}^{-1}\right)$ and chitosan $\left(\mathrm{Mw} \approx 160 \mathrm{~kg} \cdot \mathrm{mol}^{-1}\right.$, degree of acetylation $\left.=15 \%\right)$ led to hydrogels with controllable properties in terms of elasticity and strength. In this work, we performed desalting by dialysis of high ionic strength solutions of mixed polyelectrolytes and showed that the control of the $\mathrm{pH}$ during the polyelectrolyte assembly greatly impacts the mechanical properties of the hydrogel. First, for pHs from 5.5 to 7.5 , a slight coacervation was observed due to low chitosan protonation and poor polyelectrolyte associations. Then, for pHs from 3.0 to 5.5, coacervation and syneresis led to free-standing and easy to handle hydrogels. Finally, for pHs from 2.0 to 3.0 (close to the pKa of the hyaluronic acid), we observed the unusual stretchability of these hydrogels that could arise from the pre-folding of hyaluronic acid chains while physical crosslinking was achieved by hyaluronic acid/chitosan polyelectrolyte complexation.
\end{abstract}

\title{
1 Introduction
}

Polyelectrolytes (PEs), either synthetic or natural, are macromolecules bearing ionizable groups that can dissociate in aqueous solution. Thus, they are susceptible to establish electrostatic interactions with ions or macro-ions to form a wide variety of materials such as nanoparticles, ${ }^{1,2}$ hydrogels, ${ }^{3,4}$ scaffolds, ${ }^{5}$ or coacervates. ${ }^{6}$ Complex coacervation is commonly described as a phase separation of PEs which results from electrostatic interactions between oppositely charged macro-ions. PEs have been shown to be able to form coacervates with either proteins, ${ }^{7-9}$ micelles, ${ }^{10,11}$ dendrimers; ${ }^{12}$ oppositely charged PEs can also form coacervates. ${ }^{13-15}$ In the case of PE-PE complex coacervation, the term "coacervate" was 
attributed to the dense PE-rich phase, still containing a high amount of solvent, in equilibrium with a PE-poor phase such as in gum arabic /gelatin systems. ${ }^{16}$

Among PEs, polysaccharides are envisioned for biomedical applications, in particular for their biocompatibility and low toxicity. In this work, we studied the complex coacervation of hyaluronic acid (HA) and chitosan (CS). HA is a weak polyanion, with a disaccharide repeat unit composed of D-glucuronic acid and $\mathrm{N}$-acetyl-D-glucosamine, alternatively linked by $(\beta$ $>1,4)$ and $(\beta->1,3)$ glycosidic bonds; the pKa of the carboxyl group is 2.9. HA is widely present in the extracellular matrix of various tissues of the human body, such as in skin, cartilage, synovia and vitreous humor. HA exhibits some interesting features such as antiinflammatory properties ${ }^{17}$ and plays an important role in various processes of tissue regeneration. ${ }^{18}$ On the other hand, CS is the only naturally occurring cationic polysaccharide at slightly acidic $\mathrm{pH}(p K a=6.2-6.7)$. It is usually obtained from the partial of full $\mathrm{N}$ deacetylation of chitin, which is an abundant polysaccharide present in the exoskeleton of crustaceans or the endoskeleton of cephalopods. CS is a copolysaccharide of N-acetyl-Dglucosamine and D-glucosamine units linked by $(\beta->1,4)$ glycosidic bonds. It is defined by its degree of acetylation (DA) corresponding to the molar fraction of $\mathrm{N}$-acetylated residues and is known for its mucoadhesive properties, ${ }^{19}$ its bioactivity, biodegradability as well as a low toxicity. $^{20}$

Due to the desirable intrinsic properties of each polysaccharide, biomaterials containing $\mathrm{HA}$ and CS are actually widely studied. For example, many studies focused on HA/CS complexes which can be nanoparticles or micro-gels for drug-delivery, ${ }^{2,21,22}$ films, $^{23}$ hydrogels for osteoarthrosis therapy, ${ }^{24}$ but few of them reported the presence of coacervates. In 2015, Kayitmazer et al. published an in-depth study of the complex coacervation between HA and $\mathrm{CS}$, in the case of rather diluted systems and for $\mathrm{HA}$ with a molar mass ranging between 50 
$\mathrm{kg} \cdot \mathrm{mol}^{-1}$ and $750 \mathrm{~kg} \cdot \mathrm{mol}^{-1}{ }^{25}$ They pointed out that the phase separation was highly dependent on parameters such as $\mathrm{pH}$, charge ratio and ionic strength, giving rise to coacervates or precipitates. Recently, we reported a novel and controlled process of complex coacervation by desalting $\mathrm{HA} / \mathrm{CS} /$ sodium chloride $(\mathrm{NaCl})$ mixtures. ${ }^{26}$ In these conditions (i.e. high polymer concentration, molar mass of both PEs, DA, charge density) a biphasic system was obtained in which the polyelectrolyte-rich phase is so dense that the coacervates led to a stiff hydrogel and the polyelectrolyte-poor phase contained mainly water. The obtained materials are then solid systems, which have to be differentiated from the usual liquid coacervates. ${ }^{27,28}$ The present work reports on the drastic impact of $\mathrm{pH}$ on the $\mathrm{HA} / \mathrm{CS}$ complex coacervation (and subsequent gel formation) performed under desalting conditions. The effect of $\mathrm{pH}$ is mainly discussed in relation to the HA behavior and conformation in solution, the latter being linked to the mechanical properties and the nanostructure of the final stretchable HA-CS hydrogels (see video in supporting information).

\section{Experimental}

\subsection{Materials}

Sodium hyaluronate produced by fermentation of Streptococcus Equi was purchased from HTL-biotechnology (Javené, France) with a molar mass $M w \approx 900 \pm 100 \mathrm{~kg} \cdot \mathrm{mol}^{-1}$ measured by Size Exclusion Chromatography coupled with a multi-angle light scattering (SEC-MALLS) (phosphate buffer at $\mathrm{pH} 7.1$ and columns Agilent PL aquagel-OH mixed-H and $-\mathrm{M}$ ). CS obtained from shrimp shell with a medium $M w$ and low DA was purchased from Mahtani chitosan Pvt. Ltd. India (DA $\approx 1 \%$ measured by ${ }^{1} \mathrm{H} N M R, M w=150 \mathrm{~kg} \cdot \mathrm{mol}^{-1}$ and dispersity $Ð=$ $M w / M n=1.9)$. The CS raw material was further purified by dissolution at $0.5 \%(w / v)$ in diluted acetic acid aqueous solution and by filtering the resulting solution on successive 
cellulose Millipore ${ }^{\circledR}$ membranes of decreasing porosity ranging from $3 \mu \mathrm{m}$ to $0.22 \mu \mathrm{m}$, allowing the elimination of all insolubles. The purified CS was precipitated with a $29 \%$ ammonium hydroxide solution by increasing $\mathrm{pH}$ around 8 - 9. Repeated washings with deionized water were necessary to remove the excess of ammonia and recover neutral $\mathrm{pH}$. Then, CS was freeze-dried.

The purified CS was N-reacetylated according to Vachoud et al. ${ }^{29}$ Briefly, CS was dissolved in a water/1,2-propanediol mixture $(1 / 1(\mathrm{v} / \mathrm{v}))$. Then, acetic anhydride was diluted in propanediol and added dropwise. The $\mathrm{N}$-reacetylated CS was isolated by precipitation with aqueous ammonia and repeated washings with deionized water until neutrality and finally freeze-dried. In this study, only CS with a DA around $15 \%$ was investigated.

\subsection{Methods}

\subsubsection{Chitosan characterization}

The DA was calculated by the Hirai et al. method by ${ }^{1} \mathrm{H}$ NMR spectroscopy on a Brucker Avance III $400 \mathrm{MHz} 5 \mathrm{~mm}$ at $300 \mathrm{~K}^{30}$

The mass average molar mass $M w$ and the dispersity $(\Theta)$ were measured by size exclusion chromatography (2500 and 6000 PW TSK gel columns from Tosohaas) coupled online with a differential refractometer (Wyatt Optilab T-rEx) and a multi angle laser light scattering detector (Wyatt Dawn EOS) operating at $\lambda=633 \mathrm{~nm}$. A degassed $0.2 \mathrm{M}$ acetic acid $/ 0.15 \mathrm{M}$ ammonium acetate buffer, at $\mathrm{pH} 4.5$, was used as eluent. The flow rate was maintained at $0.5 \mathrm{~mL} / \mathrm{min}$. We used the values of refractive index increments $(d n / d c)$ determined independently for each DA in a previous study. ${ }^{31}$

The residual water contents of HA and CS were determined by thermogravimetric analysis (TA Instrument TGA Q500). 


\subsubsection{Viscosity measurements of HA solutions}

The viscosity of a $2 \%(w / v)$ HA solution was measured at various $\mathrm{pHs}$ using an AR2000 rheometer from TA instruments. The reference solution was prepared by dissolving HA in distilled water, $\mathrm{pH}=6.1$ to reach a concentration of $1.8 \%(\mathrm{w} / \mathrm{v})$. From this mother solution, we prepared different solutions by adjusting the $\mathrm{pH}$ by addition of $\mathrm{HCl}$ aqueous solution or $\mathrm{NaOH}$ aqueous solution. We used a $25 \mathrm{~mm}$ cone-plate geometry with an angle of $4^{\circ}$ and a truncation of $116 \mu \mathrm{m}$. The temperature was fixed at $298 \mathrm{~K}$ thanks to a Peltier plate and the shear rate varied between $10^{-3} \mathrm{~s}^{-1}$ and $100 \mathrm{~s}^{-1}$ in continuous mode. The Newtonian viscosity $\eta_{0}$ was then determined from the plateau at low shear rates. Each sample was analyzed 3 times. Time and temperature sweep measurements were performed using a $25 \mathrm{~mm}$ plateplate geometry, in oscillatory mode at an angular frequency of $10 \mathrm{rad} / \mathrm{s}$. The linear domain was determined by a strain sweep at $10 \mathrm{rad} / \mathrm{s}$. Hence, the strain was fixed at $1 \%$ in order to stay in the linear domain.

\subsubsection{Static Light Scattering (SLS)}

Measurements were carried out with an 18 angles Wyatt Dawn EOS system. The normalization was performed with a solution of $10 \mathrm{mg} / \mathrm{mL}$ of polyethylene glycol purchased from Sigma Aldrich (Saint Quentin Fallavier, France) with $M w=12 \mathrm{~kg} \cdot \mathrm{mol}^{-1}$. HA solutions with concentrations ranging from 0.1 to $1 \mathrm{mg} / \mathrm{mL}$ were prepared by an overnight dissolution of sodium hyaluronate in a phosphate buffer (containing $\left[\mathrm{Na}_{2} \mathrm{HPO}_{4}\right]=0.043 \mathrm{~mol} / \mathrm{L}$ and $\left.\left[\mathrm{KH}_{2} \mathrm{PO}_{4}\right]=0.0231 \mathrm{~mol} / \mathrm{L} ; \mathrm{pH}=7.1\right)$ and placed in scintillation vials for analysis. The solvent was filtered at $0.22 \mu \mathrm{m}$. The HA solutions were filtered at $0.45 \mu \mathrm{m}$ before analysis. The $\mathrm{pH}$ was then adjusted using filtered aqueous solutions of $1 \mathrm{M}$ hydrochloric acid $(\mathrm{HCl})$ or $1 \mathrm{M}$ sodium hydroxide $(\mathrm{NaOH})$. 


\subsubsection{Mixing of the two polysaccharides}

The HA and CS solutions were prepared separately before mixing. Sodium hyaluronate was dissolved overnight at room temperature by mechanical stirring in $0.65 \mathrm{~mol} / \mathrm{L} \mathrm{NaCl}$ to obtain a $4.5 \%(\mathrm{w} / \mathrm{v})$ homogeneous and transparent viscous HA solution. CS was also solubilized in an aqueous $\mathrm{NaCl}$ solution at $0.65 \mathrm{~mol} / \mathrm{L}$ and acetic acid at a concentration corresponding to the stoichiometric amount of the $-\mathrm{NH}_{2}$ sites of the glucosamine residues $\mathrm{pH}$ of the CS solution around 4.5). Mechanical stirring at room temperature was performed overnight. CS solutions were then added to HA solutions respecting a 1:2 volume mixing ratio and mechanical stirring was maintained for at least $2 \mathrm{~h}$. The CS concentration depended on the expected charge ratio $r=n_{\mathrm{NH}}{ }^{+} / n_{\mathrm{COO}}{ }^{-}$(molar mixing ratios between CS glucosamine units and HA glucuronic acid units) while HA concentration in the final mixture was maintained at $3 \%(w / v)$. This charge ratio $r$ is independent of the physicochemical context since it takes into account the total possible charges borne by the two polymers. The selected $\mathrm{NaCl}$ concentration induced a charge screening, sufficient to prevent the spontaneous association of the two PEs but without causing precipitation of the parent solutions (in particular CS). The final homogeneous mixtures, containing $\mathrm{HA}, \mathrm{CS}$ and $\mathrm{NaCl}$ were at $\mathrm{pH}$ around 5.

The resulting mixtures were finally placed into "Spectra/Por ${ }^{\circledR} 1$ " membranes with a molar mass cut-off $M W C O=3500 \mathrm{~g} / \mathrm{mol}$ purchased from Spectrumlabs. They were then dialyzed against deionized water ( $V \approx 100$ times the volumes of the polymer solution) for a minimum of $6 \mathrm{~h}$ under gentle magnetic stirring. The $\mathrm{pH}$ of the dialysis bath was adjusted using diluted $\mathrm{NaOH}$ or diluted $\mathrm{HCl}$. 


\subsubsection{Tensile tests}

Mechanical properties of the hydrogels were analyzed by using a tensile test machine Shimadzu EZ-SX equipped with a load cell of 50 N. A pre-strain was applied to reach a force $F=0.01 \mathrm{~N}$ in order to ensure a slight pre-tension of the sample prior testing.

\subsubsection{Small angle X-ray scattering (SAXS)}

SAXS experiments were performed at the European Synchrotron Radiation Facility (ESRF) in Grenoble, France, on BM2-D2AM beamline. The hydrogels were placed in home-made sample holders of $2 \mathrm{~mm}$ thickness trapped between 2 Kapton ${ }^{\circledR}$ tapes. The incident photon energy was set to $17 \mathrm{keV}$. We used a 2D CCD X-ray detector from Ropper scientific. The sample-to-detector distance was about $1.15 \mathrm{~m}$ and the chosen beam stop had a diameter of $3 \mathrm{~mm}$. The $q$-calibration $(q=4 \pi \sin (\theta) / \lambda ; 2 \theta$ being the scattering angle) was realized thanks to a silver behenate powder standard. The scattered contribution of the empty cell and of the solvent (home-made sample holder filled with deionized water) was subtracted from the scattered intensity of the samples. The image data treatments took into account the distortion of the camera tapper, the flat field response and the dark image. The intensity was further normalized by the incident flux, the sample thickness and I-calibration was realized with a glassy carbon standard. ${ }^{32}$ The scattered intensity profiles $I(q)$ vs the scattering vector $q$ were obtained by azimuthal average of the corrected images using Bm2img software.

Additionally, in situ SAXS measurements during tensile tests were also performed thanks to a home-made remotely controlled micro-tensile test device.

\subsubsection{Small angle neutron scattering (SANS)}

SANS experiments were performed at the Institute Laue Langevin (ILL, Grenoble, France), on D11 and D33 spectrometers (experiments 9-11-1712 and 9-11-1755). A q range from 0.003 $\AA^{-1}$ and $0.4 \AA^{-1}$ was covered using multiple sample-to-detector distances (on D33: large q: $\lambda=$ 
$6 \AA$, $D=2 \mathrm{~m}$, Coll $=7.8 \mathrm{~m}$; Middle $\mathrm{q}: \lambda=6 \AA, D=12 \mathrm{~m}$, Coll $=12.8 \mathrm{~m}$ and small $\mathrm{q}: \lambda=13 \AA, D=$ $12 \mathrm{~m}$, Coll $=12.8 \mathrm{~m}$; on D11, $\lambda=6 \AA$, large q: $D=1.2 \mathrm{~m}$, Coll $=4 \mathrm{~m}$; Middle $\mathrm{q}: D=8 \mathrm{~m}$, Coll $=8$ $\mathrm{m}$ and small $\mathrm{q}: D=28 \mathrm{~m}$, Coll $=28 \mathrm{~m}$ ). The scattered intensity curves were azimuthally averaged and corrected for background scattering from the solvent and parasitic scattering. Every SANS measurement was performed under atmospheric pressure and at room temperature. The samples were prepared at least 1 day before measurements. The mixture was prepared in salted $\mathrm{D}_{2} \mathrm{O}$ and the dialysis leading to the hydrogels were also carried out in $\mathrm{D}_{2} \mathrm{O}$ or alternatively in $10 \%(\mathrm{v} / \mathrm{v})$ acetic acid in $\mathrm{D}_{2} \mathrm{O}$. The deuterated solvent allowed the reduction of the strong contribution of incoherent scattering from the hydrogenous components and ensured a better contrast. ${ }^{33}$

\section{Results}

\subsection{Influence of the $\mathrm{pH}$ on HA behavior in aqueous solution}

\subsubsection{Viscosity}

The influence of the $\mathrm{pH}$ on the low shear Newtonian viscosity, $\eta_{0}$ of a salt-free HA solution is presented in Fig. 1a. The trends were found in agreement with a previous work published by Gatej et al. ${ }^{34}$ The Newtonian viscosity at $\mathrm{pH}=6.1$ was $\eta_{0}=25.7 \pm 2.6$ Pa.s. When the $\mathrm{pH}$ was increased, we could observe a slight decrease of the Newtonian viscosity, $\eta_{0}=19.7 \pm 2.0 \mathrm{~Pa} . \mathrm{s}$ at $\mathrm{pH}=11.2$. A similar evolution was found by slightly decreasing the $\mathrm{pH} ; \eta_{0}=23.8 \pm 2.0 \mathrm{~Pa} . \mathrm{S}$ at $\mathrm{pH}=4.4$. However, this variation was not significant. At $\mathrm{pH}=3.5$, a stronger decrease in viscosity was observed $\left(\eta_{0}=14.5 \pm 1.5 \mathrm{~Pa} . \mathrm{s}\right)$, probably due to a reduction of the electrostatic interactions caused by the reduction of the charge density of HA which could yield disentanglement and chain contraction. When $\mathrm{pH}$ ranged between 2.0 and 3.0, a significant increase in viscosity occurred, leading to $\eta_{0}$ values 4 to 5 times higher than the viscosity of 
the reference solution. This was due to a further reduction of the charge density which yielded inter-chain physical interactions. We also verified that this phenomenon was reversible, and also appeared in presence of $0.65 \mathrm{M} \mathrm{NaCl}$ as shown in the top right-hand corner in Fig. 1a with values of $\eta_{0}$ similar to the salt-free solution. Finally, when the $\mathrm{pH}$ was lower than 2, we obtained again Newtonian viscosity values lower than the one obtained at $\mathrm{pH}=6.1$. In the next section, the evolution of the viscosity of $\mathrm{HA}$ aqueous solutions will be related to the conformation of HA in solution.

We also studied the influence of temperature on the complex viscosity $\left|\eta^{*}\right|$ of a $2 \%(\mathrm{w} / \mathrm{v})$ HA solution at two different pHs (Fig. 1b, see Supporting Information for other concentrations). First, an isothermal time sweep at $25{ }^{\circ} \mathrm{C}$ was performed for each solution. This test demonstrated that no evolution of $\left|\eta^{*}\right|$ was observed on both solutions after 10 minutes $\left(\left|\eta^{*}\right|=18\right.$ Pa.s and 42 Pa.s for $\mathrm{pH}=5.7$ and 2.6 respectively). A second test consisted in performing a temperature sweep from $25^{\circ} \mathrm{C}$ to $80^{\circ} \mathrm{C}$ at a heating speed of 5 ${ }^{\circ} \mathrm{C} / \mathrm{min}(\omega=10 \mathrm{rad} / \mathrm{s}$ and $\varepsilon=1 \%)$. For the $\mathrm{HA}$ solution at $\mathrm{pH}=5.7$, a decrease of $\left|\eta^{*}\right|$ from 18 Pa.s to 8 Pa.s was observed while at $\mathrm{pH}=2.6,\left|\eta^{*}\right|$ was drastically lowered from 42 Pa.s to 6 Pa.s. This sensitivity to temperature is characteristic of the predominance of hydrogen bonding between $\mathrm{HA}$ chains at $\mathrm{pH}$ ranging between 2.0 and 3.0. 


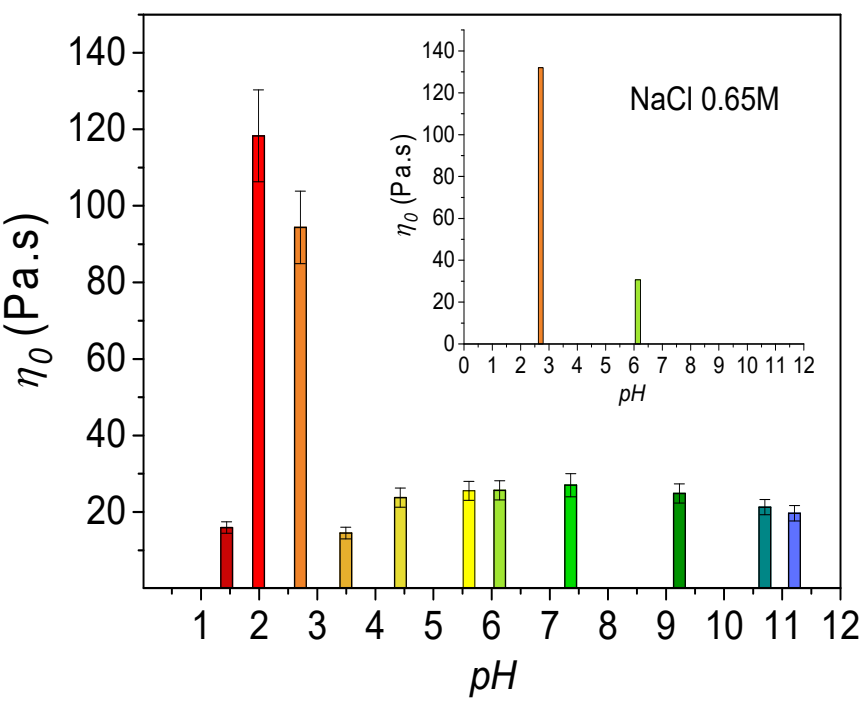

[a]

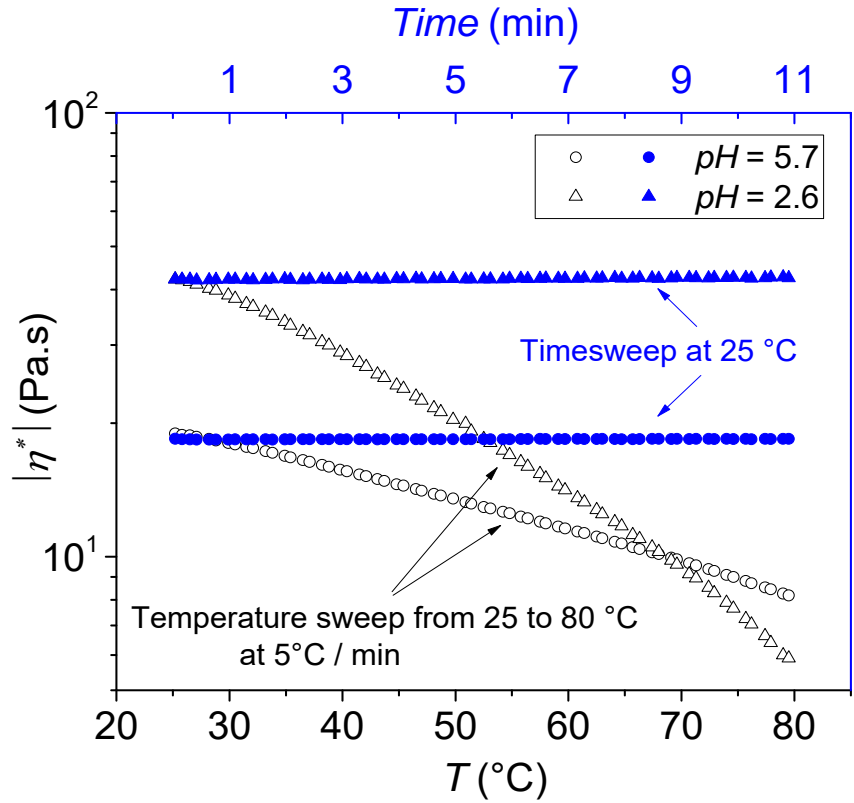

[b]

Fig. 1: [a] Influence of the $\mathrm{pH}$ on the Newtonian viscosity of an aqueous solution of HA at $1.8 \%$ (w/v); colors were chosen according to usual $\mathrm{pH}$ indicator colors. [b] Influence of the increase in temperature from $25^{\circ} \mathrm{C}$ to $80^{\circ} \mathrm{C}$ at $5{ }^{\circ} \mathrm{C} / \mathrm{min}$ on the complex viscosity of a $2 \%$ ( $\mathrm{W} / \mathrm{V}$ ) $\mathrm{HA}$ solution. No evolution was observed when temperature was maintained at $25^{\circ} \mathrm{C}$. Experiments were performed at an angular frequency of $10 \mathrm{rad} / \mathrm{s}$ and a strain of $1 \%$. Open symbols correspond to the bottom $x$ axis: $T\left({ }^{\circ} \mathrm{C}\right)$; Filled symbols correspond to the top $x$ axis: Time (min).

\subsubsection{Conformation}

The evolution of the radius of gyration $R_{g}$ as a function of $\mathrm{pH}$ was also investigated using SLS

(Fig. 2). At $\mathrm{pH}=7.1$ ( $\mathrm{pH}$ of the phosphate buffer), the determined value was $R_{g}=110 \pm 13 \mathrm{~nm}$ and remained almost unchanged when the $\mathrm{pH}$ ranged from 3 to 10 . This value was in agreement with values detailed in the literature for similar $\mathrm{pH}$ and molar masses (e.g. 126 $\mathrm{nm}$ for $M w=1060 \mathrm{~kg} / \mathrm{mol}^{35} 101 \mathrm{~nm}$ for $\left.M w=930 \mathrm{~kg} / \mathrm{mol}^{36}\right)$. As for the viscosity, the $R_{g}$ values were highly impacted when $\mathrm{pH}$ varied between 2.0 and 3.0, with apparent $R_{g}$ values between $150 \mathrm{~nm}$ to $180 \mathrm{~nm}$ with high uncertainties, reflecting here the radius of gyration of chains aggregates. For $\mathrm{pH}=1.8, R_{g}$ was highly reduced due to the chain collapse which explains the decrease in viscosity observed at this $\mathrm{pH} ; R_{g}=81 \pm 9 \mathrm{~nm}$. 


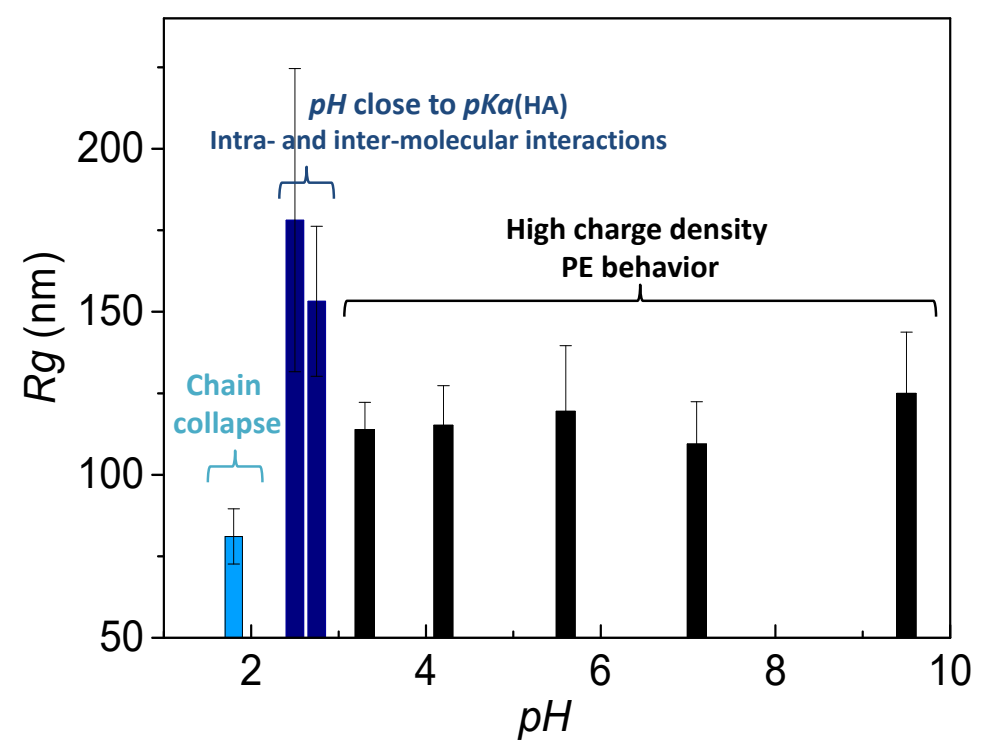

Fig. 2: Diagram showing the evolution of the radius of gyration determined by light scattering of $H A$ in aqueous solution as a function of $p H$.

\subsection{Stretchable hydrogels from $\mathrm{HA} / \mathrm{CS} / \mathrm{NaCl}$ mixtures}

In a previous study, we investigated the complexation of HA and CS using the dialysis method. ${ }^{26}$ We showed by controlling the physico-chemical parameters of CS and the charge ratio between the two polysaccharides that we were able to form various materials including complex coacervates. These hydrogel coacervates resulted from the syneresis phenomenon due to the complexation between HA and CS. This process is illustrated in Fig. 3a; pictures of a hydrogel within the dialysis membrane after dialysis is shown in Fig. $3 \mathrm{~b}$ and the resulting hydrogel is shown in Fig. 3c. Due to the long HA chains, and even if the dialysis process is slow, the complex coacervates - leading to the hydrogel formation - may not have reached equilibrium. Here, we show that the properties of the hydrogels could be controlled by changing $\mathrm{pH}$ of the dialysis bath, inducing conformational change of HA which led to unusual stretchability. The shape of the final sample was directly imposed by the shape of the dialysis membrane (Fig. 3c). By using tubular dialysis membranes with a diameter of $6.4 \mathrm{~mm}$, hydrogels with a cylinder shape and a diameter around $4.5-5 \mathrm{~mm}$ were obtained due to 
syneresis. As shown in the next section, the percentage of syneresis is dependent on $\mathrm{pH}$ and charge ratio.

\subsubsection{Percentage of syneresis}

The dependence of the percentage of syneresis with $\mathrm{pH}$ in the dialysis bath was measured at two concentrations of CS by using the following equation (Eq. ( 1 )):

$$
\text { \%syneresis }=\left(1-\frac{m_{\text {hydrogel }}}{m_{\text {total }}}\right) \times 100
$$

Where $m_{\text {total }}$ was the total mass in the dialysis membrane and $m_{\text {hydrogel }}$ was the mass of the solid phase after elimination of the supernatant and drying with an absorbing paper.

Results are shown on Fig. 3d. In both cases, the maximum syneresis was obtained at $\mathrm{pH}=4.5$, corresponding to $\mathrm{pH}$ where the two polysaccharides are fully charged (i.e. the best suited $\mathrm{pH}$ to form polyelectrolyte complexes (PECs). These values of percentage of syneresis were also higher when the concentration of CS used was higher (HA was always in excess). The syneresis could then be attributed to the formation of HA/CS PECs. As pH moved apart 4.5, the percentage of syneresis was reduced. Below $\mathrm{pH} \mathrm{2,} \mathrm{the} \mathrm{mixture} \mathrm{remained}$ transparent.

[a]
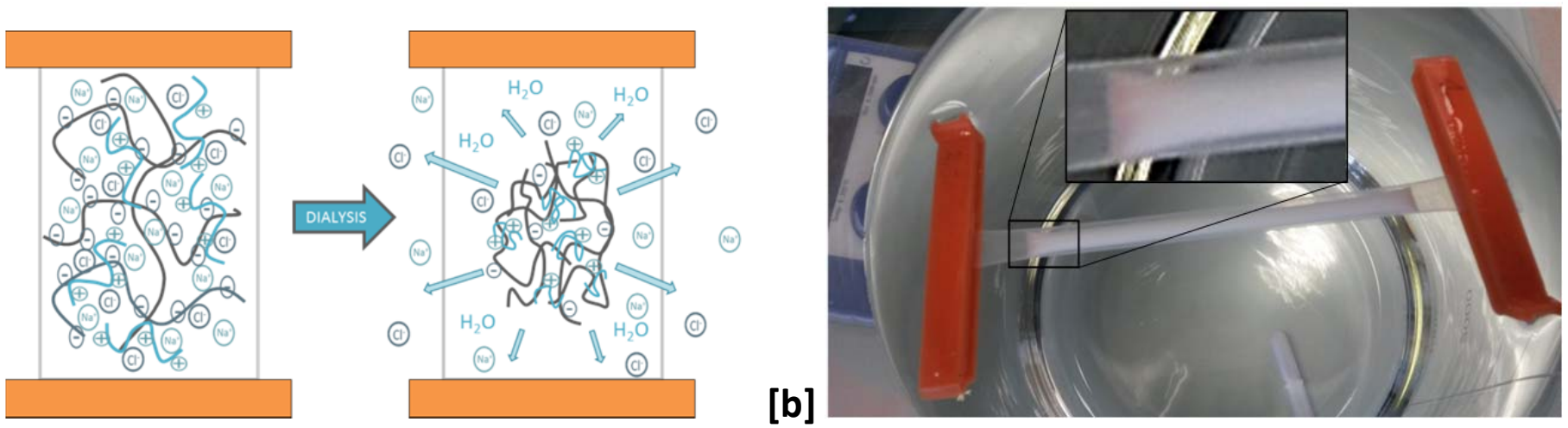

[b] 


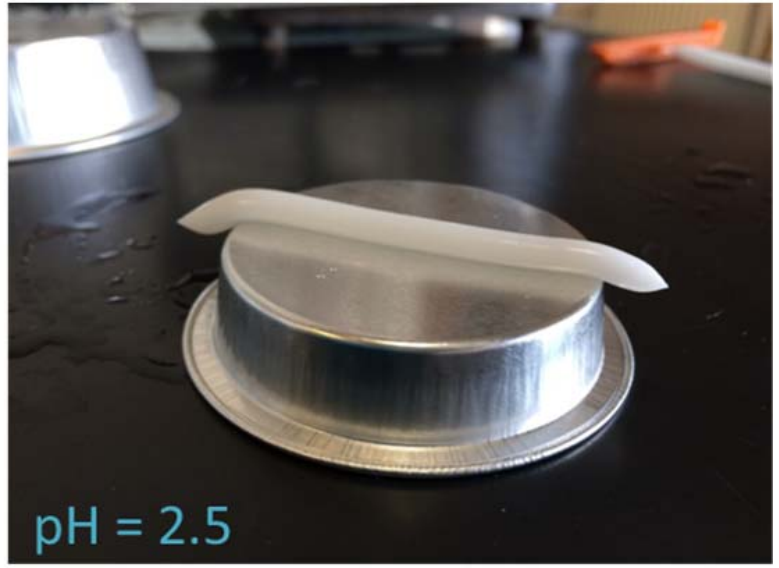

[c]

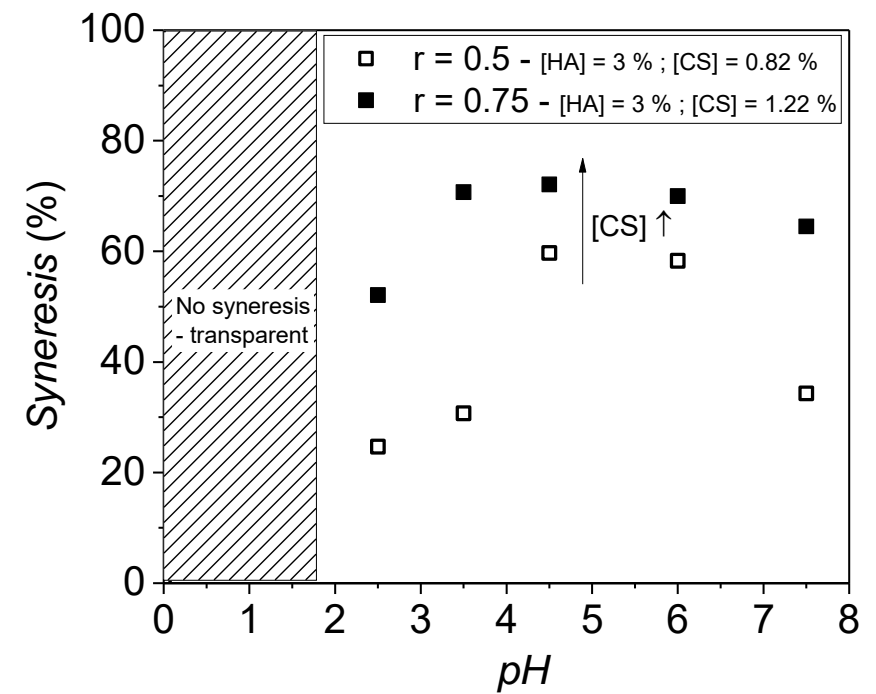

Fig. 3: Syneresis mechanism due to the formation of PECs by the desalting of HA/CS/NaCl mixture. [a] On the left, an aqueous solution containing $\mathrm{HA}, \mathrm{CS}$ and $\mathrm{NaCl}$. The desalting slowly reveals the charges of both polysaccharides. First, long-range intermolecular electrostatic interactions are created and secondary interactions as hydrophobic interactions or hydrogen bonding lead to the contraction of the system. [b] Example of HA /CS hydrogel in the dialysis membrane resulting from the syneresis after dialysis. [c] Example of a HA / CS hydrogel. [d] Percentage of syneresis induced by the controlled polyelectrolyte complexation as a function of pH and charge ratio.

By using the desalting method and by dialyzing in baths of various $\mathrm{pHs}$, we investigated the impact of $\mathrm{pH}$ on the properties of the materials. In Fig. 4, starting from a $\mathrm{NaCl}$ solution at $0.65 \mathrm{~mol} / \mathrm{L}$ containing $\mathrm{HA}$ at $3 \%(\mathrm{w} / \mathrm{v})$ and CS at $0.82 \%(\mathrm{w} / \mathrm{v})$, we summarized the different behaviors we observed depending on the $\mathrm{pH}$ of the dialysis bath. The $\mathrm{pH}$ range to observe complex coacervation (from $\mathrm{pH}=2$ to $\mathrm{pH}=6.5$ in the dialysis bath) extends beyond the $\mathrm{pH}$ range between the two pKa values of the studied polyelectrolytes (Fig. 4). The difference is likely due to the time needed for the $\mathrm{HA} / \mathrm{CS} / \mathrm{NaCl}$ mixture (initially at $\mathrm{pH}=5$ ) to reach the $\mathrm{pH}$ of the dialysis bath, and the residual charges carried by the polymers. In addition, in the $\mathrm{pH}$ range $5-7.5$, the charge density on the CS chains is too low and induced the formation of soft PEC hydrogels. Moreover, above the pKa of CS, the aggregation of the CS chains was evidenced with an increase in the apparent $R_{g}$ from $60 \mathrm{~nm}$ to $150 \mathrm{~nm} .{ }^{37}$ For pHs from 3.0 to 5.0, white and stiffer hydrogels were obtained, but these samples were still fragile when handled. Mechanical analysis was not possible since these hydrogels could not be clamped 
for tensile tests. More interestingly, when the $\mathrm{pH}$ ranged between 2.0 and 3.0, the hydrogels

exhibited unexpected mechanical properties. The formed materials were highly stretchable.

Finally, the mixture remained transparent for $\mathrm{pHs}$ below 2 .

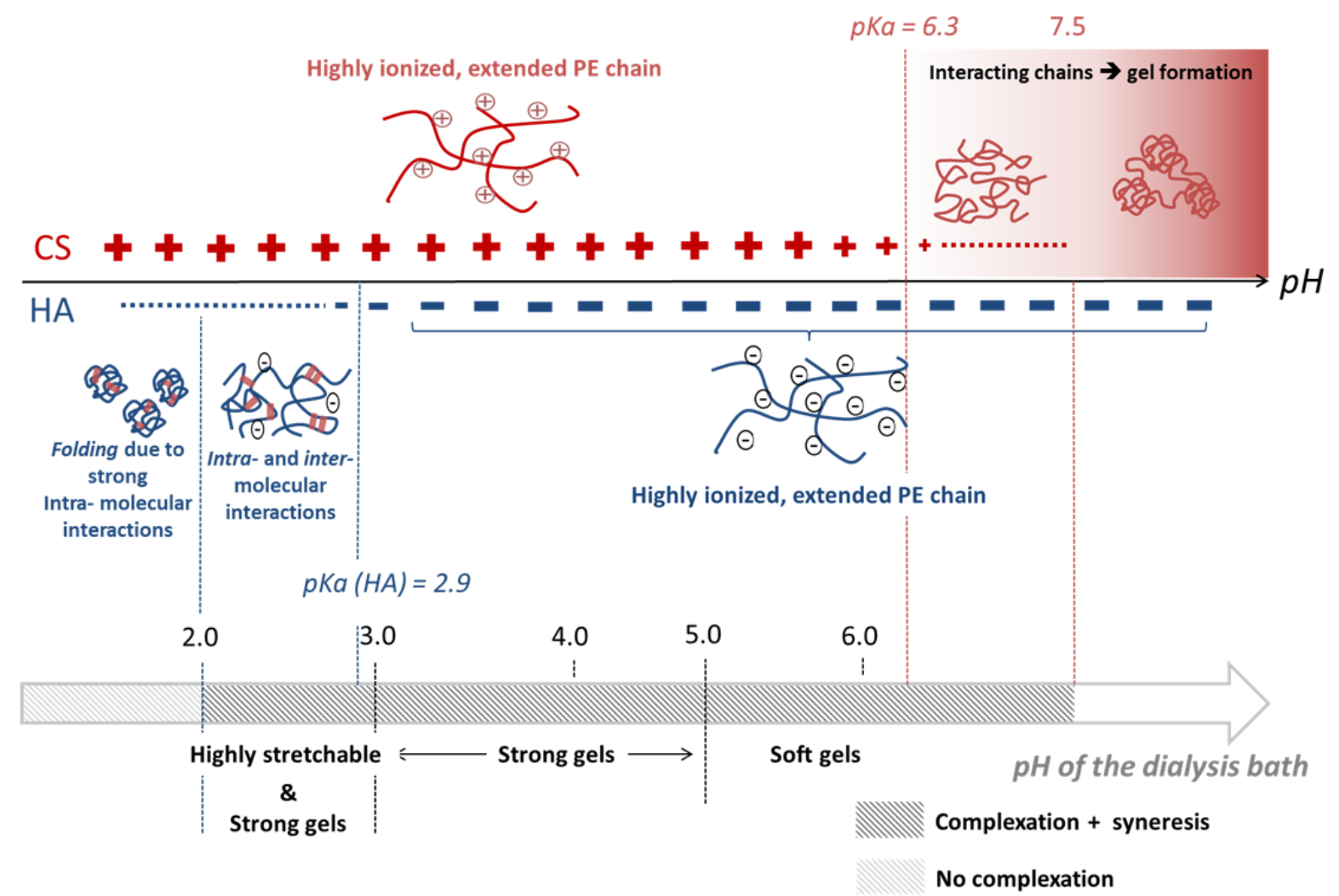

Fig. 4: Influence of $\mathrm{pH}$ on both PE conformations and influence of $\mathrm{pH}$ of the dialysis bath on the final hydrogels. The conformation of CS and HA (both alone in aqueous solution) is first presented on the top of the figure. On the one hand, at acidic pH, CS is highly ionized and exhibits a PE behavior with extended chain due to repulsive interactions. For pHs slightly higher than pKa of CS, CS adopts a random coil conformation. At alkaline $\mathrm{pHs}$, inter-chain interactions yield to the gelation of CS. On the other hand, for $\mathrm{pHs}$ higher than pKa of HA, HA chains are extended. At pHs ranging between 2.0 and 3.0, intra-and inter-molecular interactions yield to the gelation of HA. At lower pHs, intra-molecular interactions are favoured, leading to the folding of HA chains. On the bottom, we summarized on a $\mathrm{pH}$ scale the observations made on HA/CS PECS coacervates. The $\mathrm{pH}$ domain yielding stretchable and cohesive hydrogels (ranging between 2.0 and 3.0) corresponded to the gelation domain of HA.

\subsubsection{Mechanical testing of stretchable HA-CS gels}

The stretchability obtained at dialysis $\mathrm{pH}=2.5$ was further characterized by tensile tests. The hydrogels, in the form of a cylinder (diameter $\Phi \approx 4.5 \mathrm{~mm}$ and initial length $L_{0} \sim 30 \mathrm{~mm}$ ), were directly clamped on the grips. On Fig. 5a, the true stress, calculated from Eq. ( 2 ), obtained at two different crosshead speed are plotted as a function of the nominal strain $\varepsilon=$ $\Delta L / L_{0}$. These two experiments show the high deformation that these hydrogels could undergo with deformation at break of $600 \%(60 \mathrm{~mm} / \mathrm{min})$ and $1150 \%(10 \mathrm{~mm} / \mathrm{min})$ 
respectively. The Young modulus $E$ of HA/CS hydrogels with $r=0.5$ was determined by the slope of the stress-strain curve in the linear domain (below $\varepsilon=20 \%$ ) and found around $E=17 \pm 2 \mathrm{kPa}$. True stress is classically defined as:

$$
\sigma_{\text {true }}=\lambda \frac{F}{S_{0}}
$$

Where the elongation $\lambda$ is:

$$
\lambda=\frac{L_{0}+\Delta \mathrm{L}}{L_{0}}=1+\varepsilon
$$

and $S_{0}$ the initial section of the sample.

To further evaluate the plasticity behavior of such HA/CS hydrogels, we performed cyclic uniaxial tensile tests, i.e. loading and unloading cycles at constant speed.

The first test depicted in Fig. 5b consisted in realizing loading - unloading cycles at a fixed maximum strain $\varepsilon=200 \%$. After the first load, the true stress $\sigma_{\text {true }}$ was around $38 \mathrm{kPa}$. The first unload to $\sigma_{\text {true }}=0$ led to a residual deformation $\varepsilon$ of about $50 \%$. After each cycle, the true stress was reduced and the residual strain was increased, but these variations were reduced compared to the variations caused by the first loading-unloading cycle.

A second mechanical test consisted in performing loading-unloading cycles at increasing maximum stress and strains. A first stretching at low deformation was applied to reach $\varepsilon=5$ $\%$ and unloading was performed to come back to $\sigma_{\text {true }}=0$. A second cycle was applied up to $\varepsilon$ $=10 \%$ followed by unloading and successive increasing strains were applied until $\varepsilon=500 \%$. A control experiment was added on the diagram for comparison. It consisted in testing the same sample only submitted to a simple uniaxial tensile test at the same crosshead speed (see red dashed curve in Fig. 5c). The first remarkable observation was that the mechanical properties were largely affected by the successive loading and unloading cycles. Indeed, when the stretching applied exceeded the previous one, the initial loading path was 
different to the simple uniaxial tensile test, even if the cyclic load curves finally reach the simple load envelope curve at higher deformations. As a side result, it can be considered that water evaporation was negligible or did not affect the mechanical data on the duration of the experiments.

Additionally, as seen in Fig. 5, a strain-softening appeared between the loading curve and the unloading curve. Finally, the unloading and reloading slightly differed with $\sigma_{\text {reloading }}>$ $\sigma_{\text {unloading. }}$ This mechanical behavior recalls the "Mullins effect" which has been widely studied for decades in elastomer materials ${ }^{38-40}$. The Mullins model is classically used to describe the complex behavior of filled rubber materials. ${ }^{40}$ In some cases, it has also been used to describe the strain-softening of chemically crosslinked gels. ${ }^{41}$ In our study, the hydrogels could be regarded as physically crosslinked systems. Different hypotheses for the strainsoftening effect have been discussed in the literature. Various authors showed that this phenomenon could arise from different irreversible mechanisms such as chain disentanglement, ${ }^{42}$ chain slippage on fillers, ${ }^{43}$ bonding rupture at the rubber-filler interface ${ }^{40}$ and/or chain rupture at high strain. In our systems, reversible mechanisms like the rupture of hydrogen bonds, complexes rearrangements or "unzipping" of polyelectrolyte complexes are also possible. New hydrogen bonds and complexes could be formed again during unloading, which could explain the partial recovery of the stress. 


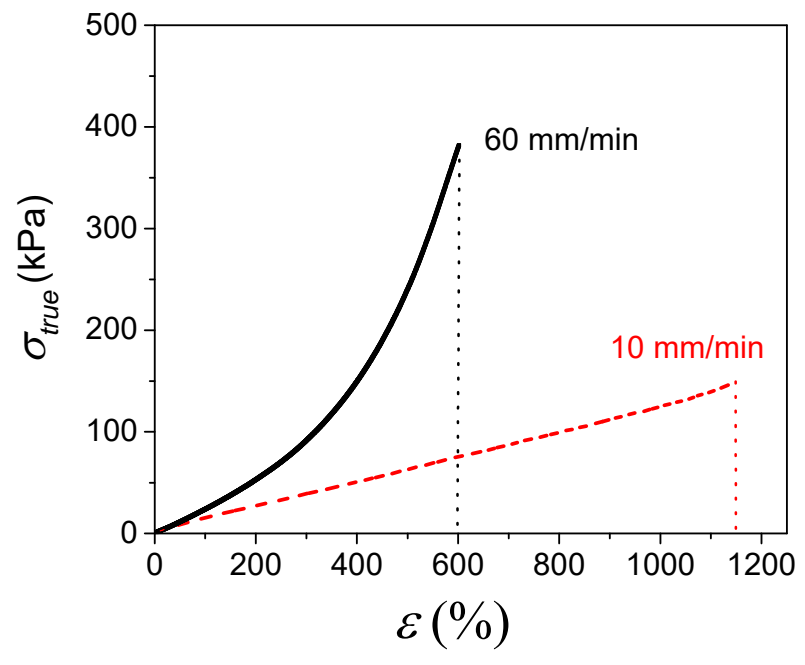

[b]

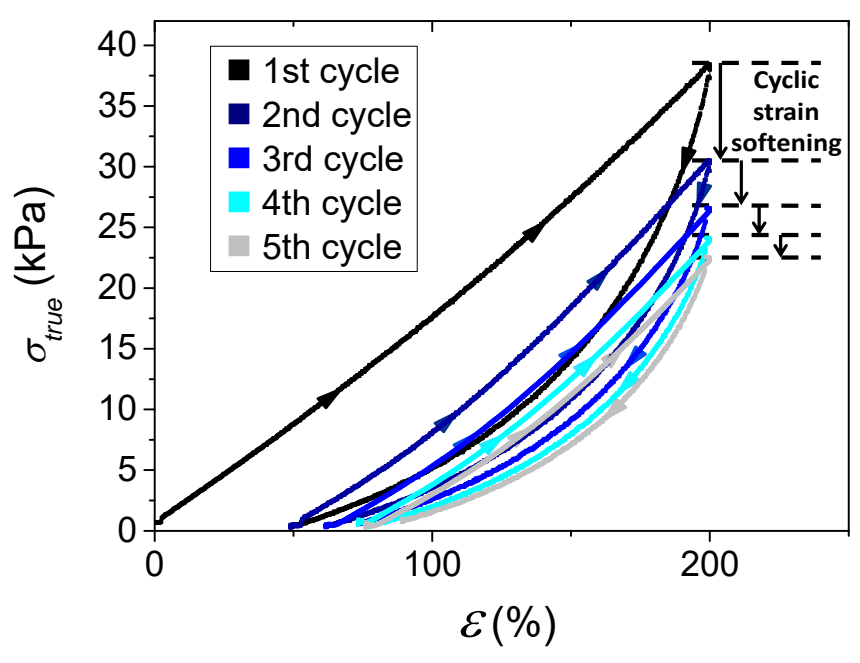

[c]
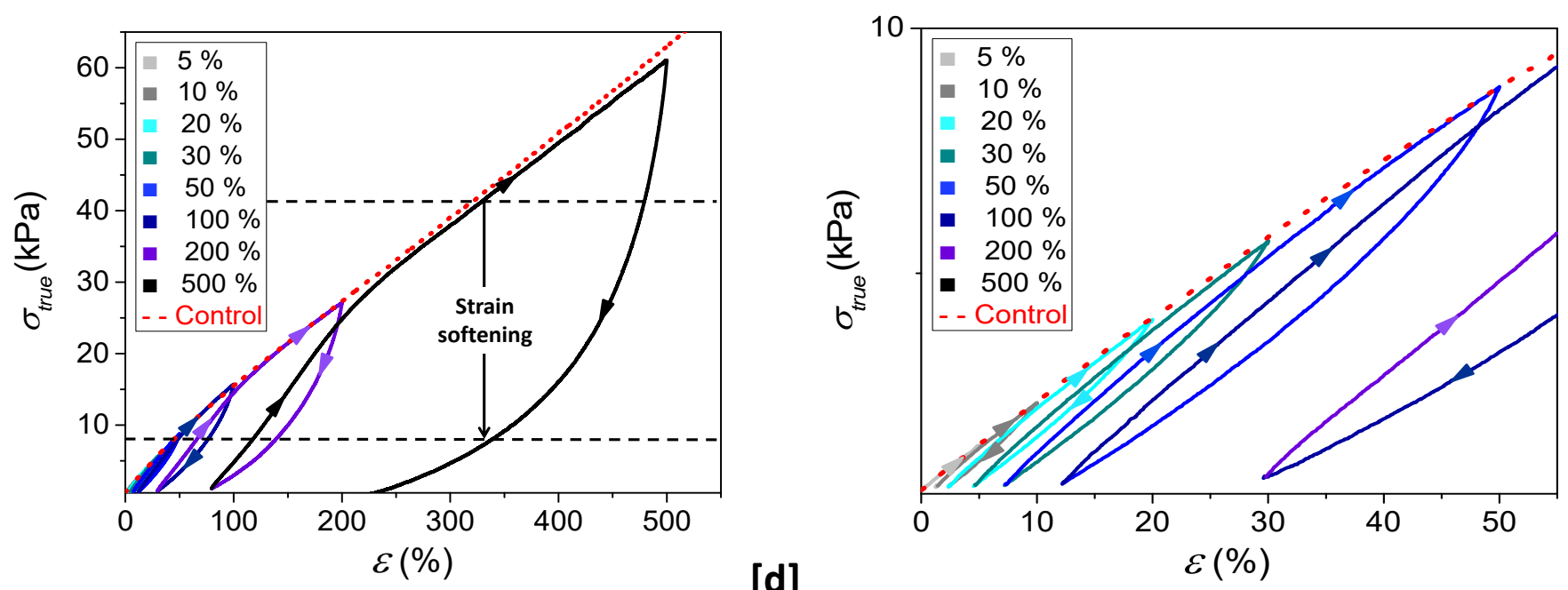

Fig. 5: Mechanical study of HA/CS hydrogel dialyzed in an acetic acid solution at $\mathrm{pH}=2.5$. Starting solution contained: [HA] $=3 \%$ $(w / v),[C S]=0.82 \%(w / v)($ with $r=0.5)$ and $[\mathrm{NaCl}]=0.65 \mathrm{~mol} / \mathrm{L}$. [a] Stress-strain curves at $10 \mathrm{~mm} / \mathrm{min}$ and $60 \mathrm{~mm} / \mathrm{min}$. [b] Dynamic tensile test: 5 cycles of stretching at $200 \%$ at a constant speed of $50 \mathrm{~mm} / \mathrm{min}$. [c] Dynamic tensile test: $5 \mathrm{cycles}$ of loading and unloading at increasing maximum stress at $10 \mathrm{~mm} / \mathrm{min}$ compared to an unidirectional stress-strain curve (- -) obtained at $10 \mathrm{~mm} / \mathrm{min}$. [d] is a magnification of the low strain zone.

Nevertheless, as hysteresis phenomena at high applied deformation were important in these systems, we also focused on the quantification of strain-induced energy dissipation using a methodology described for filled silicones. ${ }^{40}$ Large strain hysteresis has already been observed in hydrogels. ${ }^{44}$ For instance, hysteresis was seen for double network hydrogels, ${ }^{41,45}$ first introduced by Gong et al., where the energy dissipation is due to the rupture of "sacrificial" covalent bonds. However, the rupture of these bonds causes permanent damage, giving rise to high residual strain. This phenomenon was also observed in 
chemically crosslinked hybrid hydrogels ${ }^{46,47}$ where the fillers also act as a physical crosslinker due to the adsorption of the polymer onto the filler surface. In this case, the "sacrificial" covalent bonds were replaced by physical bonds, and the energy dissipation was then attributed to the polymer desorption process during loading, as it can be observed in filled rubbers. Additionally, these systems exhibited a better recoverability compared to double network hydrogels due to the re-adsorption of the polymer on the filler during unloading, leading lower residual strains. Finally, highly stretchable hydrogels with good recoverability were also designed by Sun et al. with polyacrylamide/alginate systems where the polyacrylamide was chemically crosslinked and the alginate was ionically crosslinked through the addition of calcium ions. Then, energy dissipation was achieved by unzipping ionic crosslinks. $^{44}$

In this work, large hystereses were observed; they are characteristic of large energy dissipation with high residual strain. As shown in Fig. 6a, the area $(I+S)$ under the loading curve corresponded to the mechanical energy input $W_{1+S, i}$ at strain $\varepsilon_{i}$ while the area $S$ under the unloading curve corresponded to the restitution of the stored mechanical energy $W_{s, i}$. The area I between the loading and the unloading curves thus corresponded to the apparent dissipated energy $W_{l, i}$. As successive stress-strain cycles were performed, a given loading curve was impacted by previous loadings, as seen in Fig. 5c. Finally, to evaluate rigorously the total dissipated energy $W_{D, i}$ for a given strain $\varepsilon_{i}$, we took into account the area I' between the loading curve of an uniaxial simple tensile test (dashed curve in Fig. 6a) and the i-th loading curve (solid curve in Fig. 6b). Hence, the total dissipated energy was $W_{D}=\left(W_{l}+W_{l^{\prime}}\right)$. Finally, we investigated the evolution of the Mullins ratio defined as $R_{M}=W_{D} /\left(W_{D}+W_{S}\right)$ with strain. Mullins ratio increased with the applied strain (see Fig. 6). This observation naturally indicates that the dissipated energy, which in our systems probably arose from the 
rupture of physical bonds or PECs "unzipping", increased with the applied strain. For strain values until around $100 \%$, values of $R_{M}$ were below 0.5 , which means that at least $50 \%$ of the input energy was restored during unloading. For strain values higher than $100 \%$, the dissipated energy was high with $R_{M}>0.5$, i.e. $W_{D}>W_{s}$.
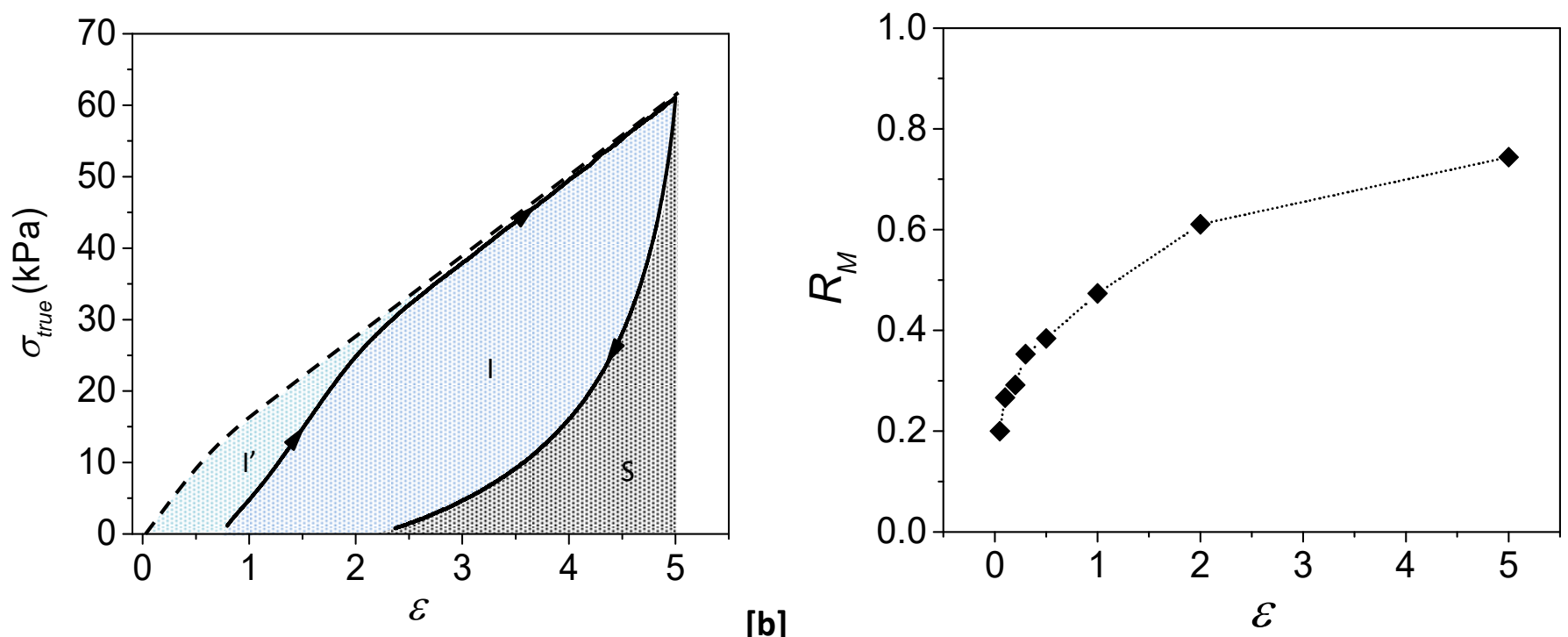

[b]

Fig. 6 : [a] Methodology for the calculation of the dissipated energy due to stretching during successive loading and unloading experiments. For instance, [a] shows a typical hysteresis loop for a HA/CS hydrogel dialyzed in sodium hydroxide solution ([HA] = 3\% $(w / v) ;[C S]=1.6 \%(w / v)$ ) presenting the stored (area $S$ ) and the total dissipated energy (area $\left.\left(I+I^{\prime}\right)\right)$ during last loading-unloading cycle taken from Fig.5c corresponding to a stretching at $500 \%$ strain (solid line graph). Dashed line graph corresponds to the loading curve of an unidirectional stress-strain curve. [b] shows the evolution of the Mullins ratio as a function of the strain $\varepsilon$.

\subsubsection{Nanostructure by SAXS and SANS.}

SAXS and SANS experiments were carried out to analyze the nanostructure of the hydrogels.

The scattered intensity of our systems (see Fig. 7) presented two well-defined regimes with a change of slope at $q$ values around $0.02-0.03 \AA^{-1}$. Many mathematical models could be used to determine the structural features of our systems - such as the correlation length model used by da Silva et $a l .{ }^{48}$ we have chosen to use the model already used by our group for similar systems. ${ }^{1,3,26}$ The scattered intensity $I(q)$ can then be decomposed in two contributions. 


$$
I(q)=\frac{A}{q^{\alpha}}+\frac{B}{q^{\beta}}
$$

For several systems investigated here at $\mathrm{pH} \leq 3.5$, Eq. 4 could be successfully used to analyze the SAXS and SANS scattering patterns. However, an additional term was needed to fully describe our systems. Indeed, a shoulder was appearing at intermediate $q$ values, in particular for the scattering diagrams of the HA-CS hydrogels at $\mathrm{pH}$ higher or equal to 4.5. As HA was in excess in the hydrogels $(r=0.5)$, the additional contribution was attributed to the presence of the polyelectrolyte peak of HA, centered on $q_{0}$, of unassociated HA chains, modeled as a Lorentzian function: ${ }^{49}$

$$
I_{P E}(q)=\frac{C}{1+\left(\left(q-q_{0}\right) \times \xi\right)^{2}}
$$

In SANS experiments, the available $q$ range was higher than in SAXS and lower $q$ values were accessible. To fully describe all the features observed in SANS scattering diagrams (for $\mathrm{pH}>4$ ), we introduced an additional mid-scale contribution under the form of a Guinier term $I_{G}(q)$ as follows:

$$
I_{G}(q)=D \exp \left(-\frac{R_{G}{ }^{2} q^{2}}{3}\right)
$$

where $R_{G}$ is the radius of the scattering objects.

Finally the final $I_{\text {SANS }}(q)$ expression we used for the modeling of SANS diagrams was:

$$
I_{S A N S}(q)=\frac{A}{q^{\alpha}}+\frac{B}{q^{\beta}}+\frac{C}{1+\left(\left(q-q_{0}\right) \xi\right)^{2}}+D \exp \left(-\frac{R_{G}^{2} q^{2}}{3}\right)
$$

The scattering pattern thus contained four terms corresponding to the multi-scale and complex structural organization of HA-CS hydrogels.

In Fig. 7a, we represented the intensity $I(q)$ as a function of the scattering vector $q$ from SAXS experiments. Every hydrogel was adequately fitted with the proposed model. For pHs 7.5, 
6.0 and 4.5 , the coefficient values $\alpha$ and $\beta$ were maintained at 4 and 1 respectively for modeling. The corresponding position $q_{0}$ of the PE peak thus decreased from $0.042 \AA^{-1}$ to $0.014 \AA^{-1}$. These results are consistent with the values we already reported for the PE peak position of HA. ${ }^{26}$ Additionally, it was also in agreement with the fact that the amount of free HA available decreased from $\mathrm{pH} 7.5$ - where the charge density of CS is low (i.e. where few PECs are likely to be formed) to $\mathrm{pH} 4.5$ - where HA and CS are fully charged (i.e. which must led to more PECs). For pHs 3.5 and 2.5 , the scattering diagrams slightly differed and no longer exhibited a shoulder at intermediate $q$ values. As the $\mathrm{pH}$ was close to the pKa of the carboxylic acid moieties of HA, we expect the charge density to be highly reduced, which could lead to the vanishing of the PE peak. The model could then be simplified and reduced to two power laws (see Eq (4)) with $\alpha$ around $3.6-3.7$ at low $q$ values, and $\beta$ at high $q$ values around $0.9-1$ (see discussion below).

On the other hand, SANS diagrams presented a different shape with an additional contribution at intermediate $q$ values (in the $q$-range from $9 \cdot 10^{-3}$ to $10^{-2} \AA^{-1}$ ). However, the modeling was also adapted for the analysis of the SANS diagrams and the values of the coefficients $\alpha$ and $\beta$ were quite comparable to those found by the analysis of SAXS patterns (see Fig. 7b). 

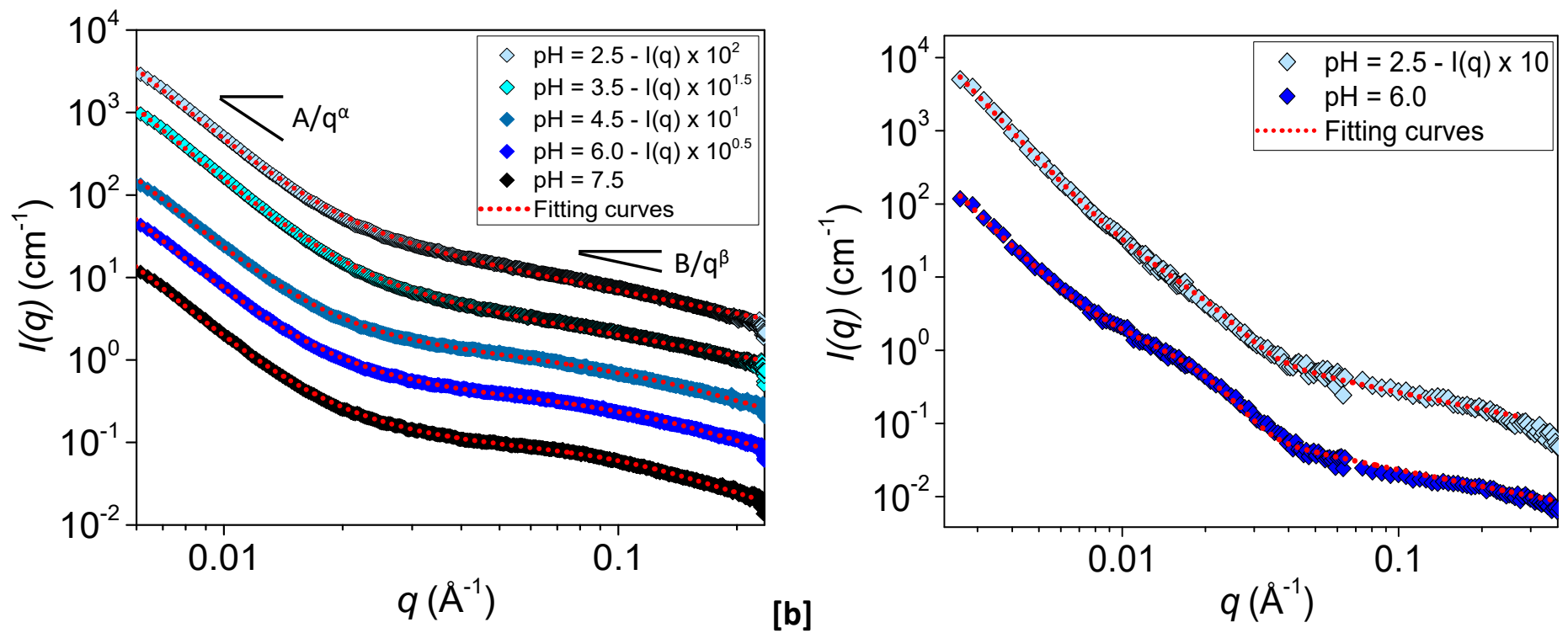

Fig. 7: SAXS [a] and SANS [b] diagrams of hydrogels obtained by dialysis from a HYA/CS/NaCl mixture containing HA at $3 \%$ (w/v), CS at $0.82 \%(\mathrm{w} / \mathrm{V})$ and $\mathrm{NaCl}$ at $0.65 \mathrm{~mol} / \mathrm{L}$. On both graphs, the red dotted curves are fitting curves. On [a], the intensity at pH 7.5 is has not been modified, the other absolute intensities have been multiplied by successive powers of 110 for clarity. On [b], the intensity at pH 6.5 is has not been modified, and the intensity at pH 6.0 has been multiplied by 10 .

\subsubsection{Scattered patterns under stretching}

In situ tensile tests were performed on the hydrogel to follow the evolution of the nanostructure under stretching by SAXS. These tests were performed thanks to a simple homemade micro-tensile test equipment composed of two crossheads, one of them being mobile and guided by two stainless-steel guide bars and displaced by means of a threaded shaft, a DC electric motor and a LVDT sensor to control the cross-head position. The hydrogel was stretched in the vertical direction (Fig. 8a). The scattered patterns are shown on Fig. 8b. The absolute intensity $I(q)$ was calculated supposing that the deformation was a constantvolume process. Thus, we considered that during the tensile test, the width $w$ of the sample, initially $w_{0}=4.5 \mathrm{~mm}$, followed an evolution during the tensile test as $w=w_{0} / \lambda^{1 / 2}$ where $\lambda$ is the elongation. Before being stretched, the hydrogel presented an isotropic pattern (Fig. 8b $\left.\mathrm{n}^{\circ} 1\right)$. By applying a strain of $200 \%$ of the initial length $(\lambda=3)$, the pattern became highly anisotropic, and the central scattered intensity increased perpendicularly to the stretching direction and decreased in the parallel direction, showing that the alignment of large scale 
objects is occurring at the micro and nano scales (Fig. $8 b-n^{\circ} 2$ ). Finally, by relaxing the hydrogel to a zero-strain $(\lambda \approx 1.75)$, the pattern was almost isotropic again, showing the strain reversibility in the investigated scales (Fig. $8 b-n^{\circ} 3$ ), whereas tensile tests showed significant strain reversibility at the macroscopic scale. Apparently, stretching mostly influenced the low $q$ domain, leaving the high $q$ regime almost unchanged.

[a]

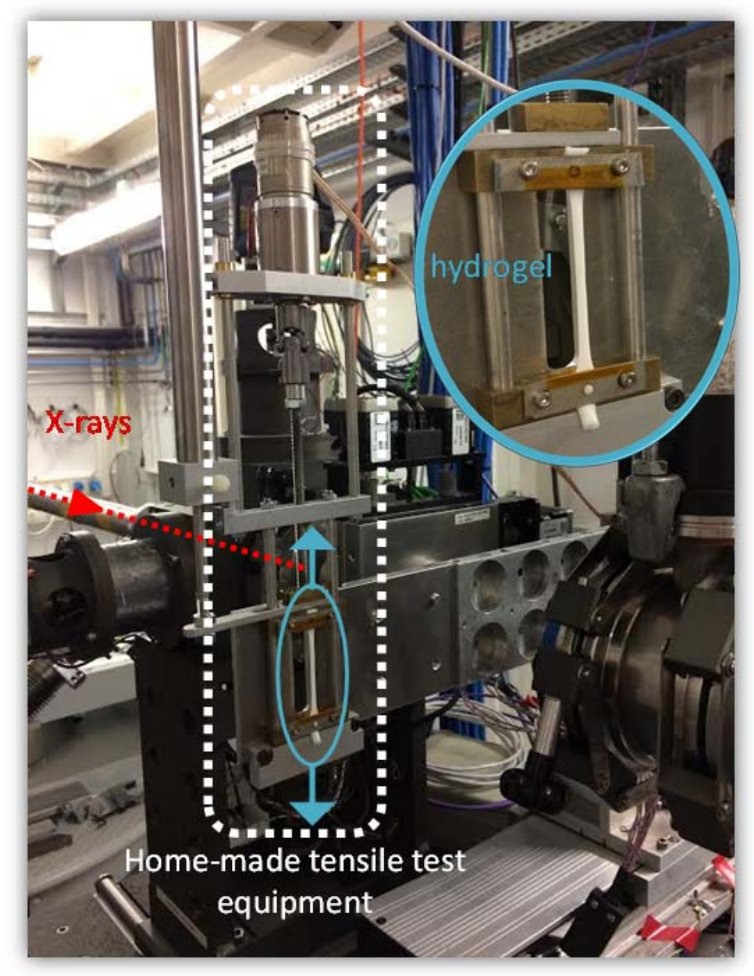

[b]

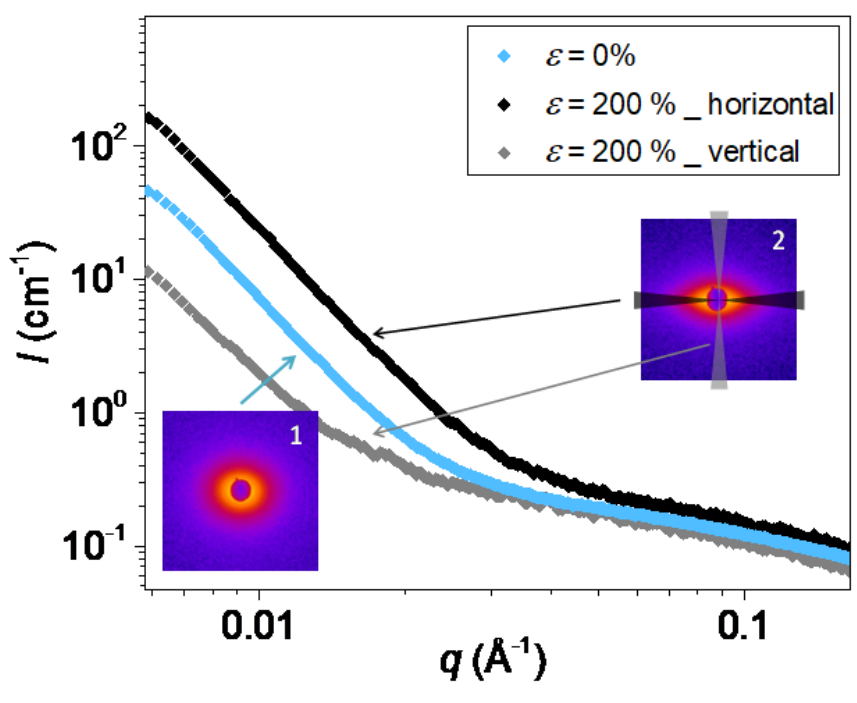

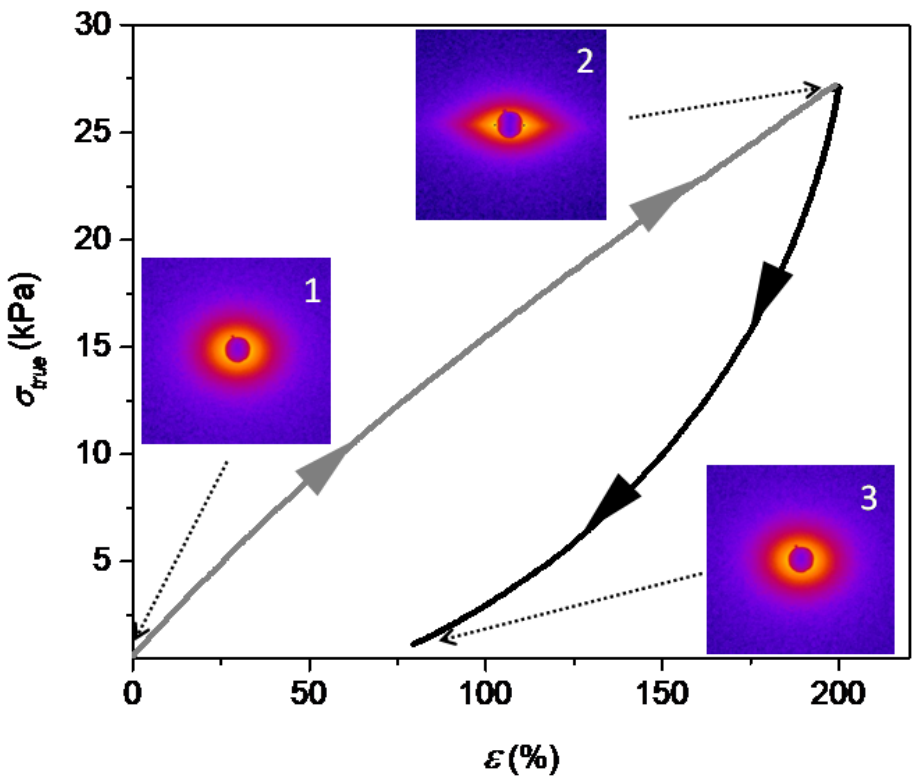

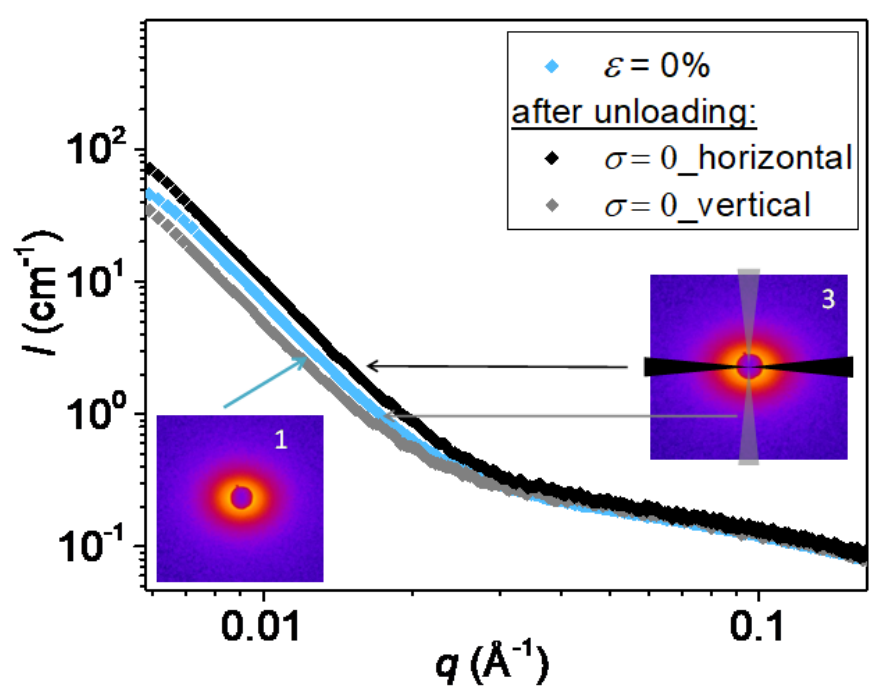

Fig. 8: In situ tensile tests on a $\mathrm{HA} / \mathrm{CS}$ hydrogel containing $[\mathrm{HA}]=3 \%(w / v)$ and $[\mathrm{CS}]=0.82 \%(w / v)$. [a] is the presentation of the homemade tensile test machine set up on BM2-D2AM beamline at ESRF, Grenoble - France. [b] shows the images obtained before (image 1 shows an isotropic pattern), after loading (image 2 shows a strongly anisotropic pattern) and unloading at $200 \%$ strain (image 3 
exhibits an isotropic pattern showing strain reversibility). [c] shows the scattering diagrams of the hydrogel before loading (blue symbols and after loading at $200 \%$ strain horizontally (black symbols) and vertically (grey symbols). [d] presents the scattering diagrams of the hydrogel at initial state and after loading at $200 \%$ strain followed by unloading at zero-stress.

\section{Discussion}

The mechanical properties of the hydrogels obtained from the controlled complex coacervation were highly impacted by the $\mathrm{pH}$ of the dialysis bath, although the nanostructure characterization of these hydrogels by SAXS and SANS did not exhibit drastic differences in terms of scattered pattern and structural organization. A contribution coming from the polyelectrolyte behavior of HA was observed and was attributed to free HA chains, i.e. HA chain segments that are not involved in PECs. At pHs close to the pKa of the carboxylic acid moieties of $\mathrm{HA}$, the PE peak was not present anymore, due to a reduced charge density of $\mathrm{HA}$, but the scattering diagrams exhibited two regimes. At low $q$ values, the variation of the scattered intensity as $I \sim q^{-3.6-3.7}$ could be attributed to the semi-rough surface of PECs solid-like aggregates which size is in the $100 \mathrm{~nm}$ to the micron range. In these systems, the PECs act as physical crosslink nodes by forming solid-like domains in a highly stretchable HA matrix of condensed chains. At high $q$ values, the intensity varied as I $\sim q^{-0.9-1}$. This behavior was assigned to a rigid rod-like conformation of PE associations inside the PECs solid-like aggregates that can come from a "ladder-like" organization at the nano-scale.

In SANS, at intermediate $q$ values, the scattering diagrams presented a shoulder which was not observed in SAXS. This difference was probably arising from a higher contrast factor in SANS. The shoulder was even more pronounced at $\mathrm{pH}=6.0$ than at $\mathrm{pH}=2.5$. This behavior was imputed to the signature of high-density zones whose size was about $60-80 \AA$ (determined by a Guinier model). These zones were comparable in their size to CS crystallites, which were found to have the same order of magnitude ( $40 \AA$ to $60 \AA$ ) in 
previous studies. ${ }^{50,51}$ Moreover, this shoulder was much more pronounced at $\mathrm{pH}$ close to the pKa of the amines of CS, i.e. where CS deprotonation is important and where CS chains are more likely to form crystallites.

The scattering behavior of our system is very different from the scattering obtained from one-phase coacervates made of flexible polyelectrolytes: Spruijt et al.$^{52}$ where at low $q, I \sim$ $q^{-2}$ attributed to density fluctuations at large scales. Such differences in the structural organization of the coacervates are expected to lead to different mechanical properties. ${ }^{27,28}$

The impact of $\mathrm{pH}$ on the mechanical properties of the hydrogels must be related to the conformation of HA chains and their resulting charge densities in different physico-chemical contexts. In the $\mathrm{pH}$ range 5.0 - 7.5 for the dialysis step, the obtained hydrogels were not strong enough to be easily handled. Between pH 5.0 and 6.0, the charge density on CS was apparently sufficient to allow the formation of hydrogel PECs but still insufficient to confer good mechanical properties. In the $\mathrm{pH}$ range $3.0-5.0$, where the charge density of $\mathrm{HA}$ and CS was maximum, the PECs formation was favored; the hydrogels were strong enough to be manipulated, but did not exhibit stretchability properties. Finally, for a dialysis pH between 2.0 and 3.0, the PECs formation occurred to a lesser extent than in the previous higher $\mathrm{pH}$ range and it was concomitant with the conformational change of HA chains and their associations, resulting from the decrease in the macromolecule charge density. Interactions between HA macromolecules were evidenced by a drastic increase in both viscosity and in apparent $R_{g}$ observed by SLS. Hydrogen bonds were involved in this self-organization process as suggested by the decrease of the complex viscosity upon heating. Hence, the gelation taking place during dialysis within the specific $\mathrm{pH}$ range $2.0-3.0$ resulted in the formation of a double interaction network of intra- and inter-molecular hydrogen bonding of HA chains 
co-crosslinked with HA-CS PECs. These assembly contributions and the flexible coil conformation of HA chains provided the resulting hydrogel with a unique characteristic of high stretchability. The network of highly hydrated macromolecules in interaction with one another was stabilized by the formation of physical PECs crosslinks, associating the two oppositely charged PEs. Thus, the gel integrity was maintained even under high strain and this combination of interactions may contribute to the energy dissipation characterized by large strain hysteresis. On decreasing the $\mathrm{pH}$ below 2.0, the HA chains were no longer charged and collapsed in a more compact conformation than at $\mathrm{pH} 2.0-3.0$ for which the remaining charges prevented condensed chain conformations. Indeed, the radius of gyration of HA chains was lowered about 1.4-1.5 times and gels could not be obtained.

The mechanical behavior of the stretchable hydrogels, characterized by a dissipative process recalling the Mullins effect provided us with some clues about the mechanisms underlying the mechanical response with strain softening. Furthermore, the in situ tensile tests performed in SAXS indicated how the system may align when the hydrogel was submitted to stretching. A possible structural scheme is summarized in Fig. 9 which shows the nanostructure of the hydrogel containing folded HA chains, hydrogen bonds, and physical crosslinks such as $\mathrm{H}$-bonds and PECs solid-like aggregates. 


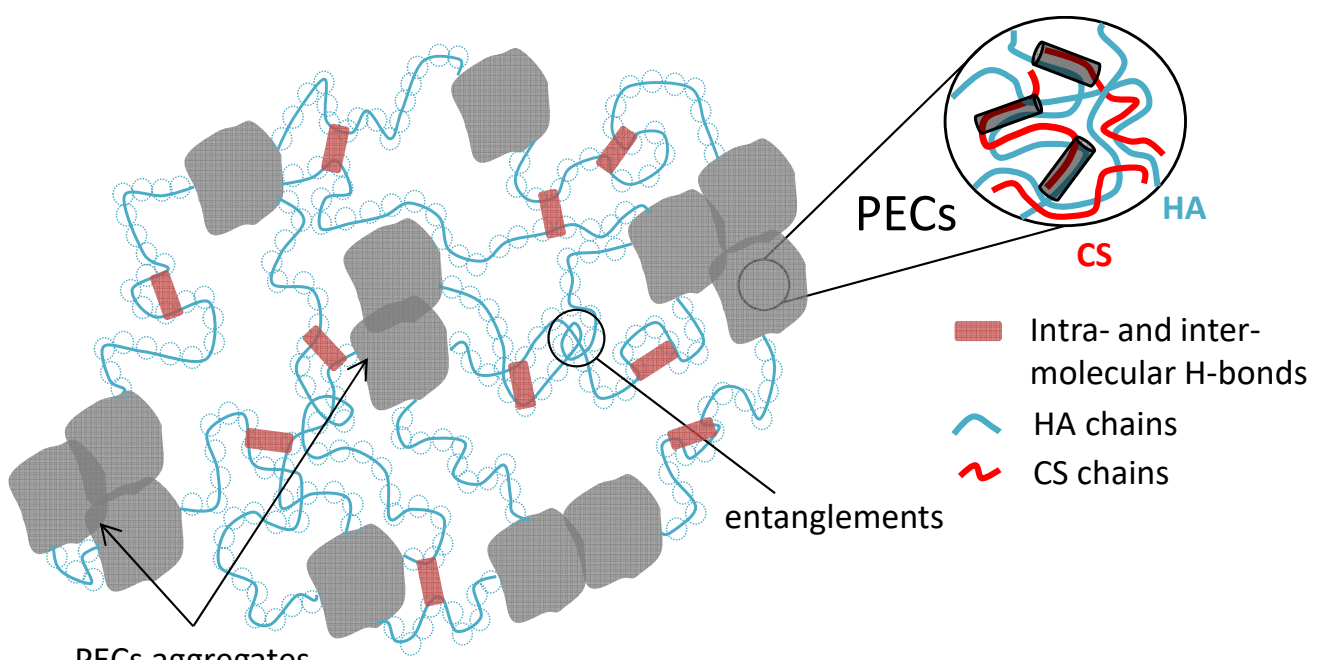

[a]

PECs aggregates

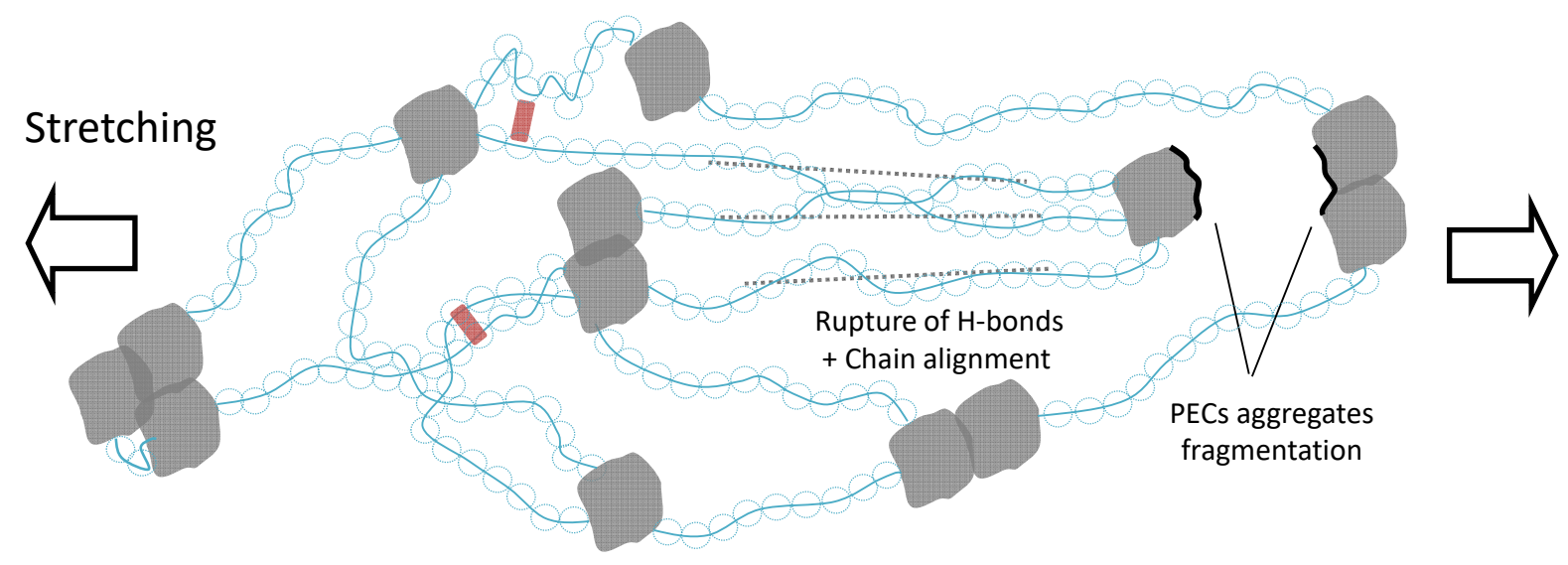

Fig. 9: Structure of HA/CS hydrogels prepared by controlled complex coacervation by dialysis in an acidic solution at $\mathrm{pH} 2.5$ when allowed to rest [a] and under stretching $[b]$.

\section{Conclusions}

HA-CS hydrogels were obtained by desalting $\mathrm{HA} / \mathrm{CS} / \mathrm{NaCl}$ mixtures at various $\mathrm{pHs}$ of the dialysis bath. The control of the dialysis $\mathrm{pH}$ allowed the tuning of the mechanical properties of the resulting hydrogels, from fragile hydrogels for $\mathrm{pHs}$ close to the pKa of the amines of CS to strong and stretchable materials for pHs slightly inferior to the pKa of the carboxylic acid moieties of HA. The unusual stretchability was explained by the folding of HA chains and the hydrogen bonds comprising intra- and inter-molecular interactions at $\mathrm{pHs}$ comprised between 2.0 and 3.0. First, the folded chains interacting with one another, form a highly entangled network which has the ability to dissipate energy through the rupture of those 
hydrogen bonds. Second, the solid-like PECs ensure the cohesion of the system by forming a semi-permanent elastic network. The properties of such stretchable hydrogels are promising and could be envisioned as being suitable for biomedical applications requiring high stretchability. Howerver, the main drawback of the HA/CS systems designed so far was that their mechanical properties were not preserved after increasing $\mathrm{pH}$ to values higher than 3.0, where the hydrogels totally lost their stretchability. As far as we know, such unusual stretchability for hydrogels based on $100 \%$ unmodified naturally-occuring polysaccharides is reported for the first time. Consequently, this work opens new insights and perspectives in the field of biomaterials.

\section{Acknowledgements}

The authors would like to thank the Institute Laue-Langevin for SANS experiments referenced as:

- SUDRE Guillaume; DAVID Laurent; DELAIR Thierry; GRILLO Isabelle and LALEVEE Gautier. (2015). Structure and Orientation in Macrogels obtained by the Desalting and the Neutralization of Solutions of Chitosan and Hyaluronic Acid. Institut Laue-Langevin (ILL) doi:10.5291/ILL-DATA.9-11-1755.

- SUDRE Guillaume; DAVID Laurent; DELAIR Thierry; GRILLO Isabelle and LALEVEE Gautier. (2014). Macrogels or Particules of Polyelectrolyte Complexes obtained by the Desalting of Solutions of Chitosan and [Dextran or Hyaluronic Acid]. Institut Laue-Langevin (ILL) doi:10.5291/ILL-DATA.9-11-1712.

We also want to thank the CRG group at ESRF (France), in particular Cyrille Rochas for his expertise for SAXS experiments on BM2-D2AM beamline, as well as Laurent Cavetier for the electrical interface of the micro-tensile test device. We are also in debt to the Centre for the 
Characterization of Polymers by Liquid Chromatography of the Institut de Chimie de Lyon for molar mass determination by SEC measurements at IMP. This work was financed by the Laboratoire ObvieLine - a Sinclair Pharma company and the ANRT - Association Nationale de la Recherche et de la Technologie through the Cifre program (Contract $n^{\circ} 402 / 2013$ ).

\section{Author contribution}

GL prepared the samples, carried out the mechanical and SAXS/SANS measurements and participated in writing the manuscript. AC performed the polymer characterization (GPC) and carried out the SALS measurements. IG (for neutron scattering) and IM (for X-ray scattering) helped review the experimental proposals, design and carry out the experiments, treat and analyze the data. KB participated in the X-ray scattering experiments. JM, SM (industrial side) and LD, AM, TD and GS (academic side) supervised the work, participated in writing the manuscript and brought their expertise at various steps for designing the materials and the experiments, carrying out some of the experiments, treat and analyze the data. 


\section{References}

1 M. Costalat, P. Alcouffe, L. David and T. Delair, J. Colloid Interface Sci., 2014, 430, 147156.

2 D. Wu and T. Delair, Carbohydr. Polym., 2015, 119, 149-158.

3 M. Costalat, P. Alcouffe, L. David and T. Delair, Carbohydr. Polym., 2015, 134, 541-546.

4 X. Wang, Y. Du and H. Liu, Carbohydr. Polym., 2004, 56, 21-26.

5 P. Coimbra, P. Alves, T. A. M. Valente, R. Santos, I. J. Correia and P. Ferreira, Int. J. Biol. Macromol., 2011, 49, 573-579.

6 C. G. de Kruif, F. Weinbreck and R. de Vries, Curr. Opin. Colloid Interface Sci., 2004, 9, 340-349.

7 X. Du, D. Seeman, P. L. Dubin and D. A. Hoagland, Langmuir, 2015, 31, 8661-8666.

8 J. J. Water, M. M. Schack, A. Velazquez-Campoy, M. J. Maltesen, M. van de Weert and L. Jorgensen, Eur. J. Pharm. Biopharm., 2014, 88, 325-331.

9 I. Morfin, E. Buhler, F. Cousin, I. Grillo and F. Boué, Biomacromolecules, 2011, 12, 859870.

10D. Li, M. S. Kelkar and N. J. Wagner, Langmuir, 2012, 28, 10348-10362.

11 L. Chiappisi, S. Prévost, I. Grillo and M. Gradzielski, Langmuir, 2014, 30, 1778-1787.

12 D. Leisner and T. Imae, J. Phys. Chem. B, 2003, 107, 8078-8087.

13 R. Chollakup, W. Smitthipong, C. D. Eisenbach and M. Tirrell, Macromolecules, 2010, 43, 2518-2528.

14 S. L. Perry, Y. Li, D. Priftis, L. Leon and M. Tirrell, Polymers, 2014, 6, 1756-1772.

15X. Liu, M. Haddou, I. Grillo, Z. Mana, J.-P. Chapel and C. Schatz, Soft Matter, 2016, 12, 9030-9038.

16H. G. B. de Jong and H. R. Kruyt, Proc. K. Akad. Van Wet. Te Amst., 1929, 32, 849-856.

17D. Foschi, L. Castoldi, E. Radaelli, P. Abelli, G. Calderini, A. Rastrelli, C. Mariscotti, M. Marazzi and E. Trabucchi, Int. J. Tissue React., 1990, 12, 333-339.

18 W. Y. J. Chen and G. Abatangelo, Wound Repair Regen., 1999, 7, 79-89.

19P. He, S. S. Davis and L. Illum, Int. J. Pharm., 1998, 166, 75-88.

20P. Baldrick, Regul. Toxicol. Pharmacol., 2010, 56, 290-299.

21 S. Al-Qadi, M. Alatorre-Meda, E. M. Zaghloul, P. Taboada and C. Remunán-López, Colloids Surf. B Biointerfaces, 2013, 103, 615-623.

22 S. T. Lim, G. P. Martin, D. J. Berry and M. B. Brown, J. Controlled Release, 2000, 66, 281-292.

23 Q. Feng, G. Zeng, P. Yang, C. Wang and J. Cai, Colloids Surf. Physicochem. Eng. Asp., 2005, 257-258, 85-88.

24 S. Kaderli, C. Boulocher, E. Pillet, D. Watrelot-Virieux, A. L. Rougemont, T. Roger, E. Viguier, R. Gurny, L. Scapozza and O. Jordan, Int. J. Pharm., 2015, 483, 158-168.

25 A. B. Kayitmazer, A. F. Koksal and E. K. Iyilik, Soft Matter, 2015, 11, 8605-8612.

26G. Lalevée, G. Sudre, A. Montembault, J. Meadows, S. Malaise, A. Crépet, L. David and T. Delair, Carbohydr. Polym., 2016, 154, 86-95.

27 Y. Liu, H. H. Winter and S. L. Perry, Adv. Colloid Interface Sci., 2017, 239, 46-60.

28E. Spruijt, M. A. Cohen Stuart and J. van der Gucht, Macromolecules, 2013, 46, 16331641.

29L. Vachoud, N. Zydowicz and A. Domard, Carbohydr. Res., 1997, 302, 169-177.

30 A. Hirai, H. Odani and A. Nakajima, Polym. Bull., 1991, 26, 87-94.

31 C. Schatz, C. Viton, T. Delair, C. Pichot and A. Domard, Biomacromolecules, 2003, 4, 641-648.

32F. Zhang, J. Ilavsky, G. G. Long, J. P. G. Quintana, A. J. Allen and P. R. Jemian, Metall. Mater. Trans. A, 2010, 41, 1151-1158. 
33 M. Shibayama, M. Nagao, S. Okabe and T. Karino, J. Phys. Soc. Jpn., 2005, 74, $2728-$ 2736 .

34I. Gatej, M. Popa and M. Rinaudo, Biomacromolecules, 2005, 6, 61-67.

35R. Mendichi, L. Šoltés and A. Giacometti Schieroni, Biomacromolecules, 2003, 4, 18051810.

36P. Gribbon, B. C. Heng and T. E. Hardingham, Biophys. J., 1999, 77, 2210-2216.

37 C. Schatz, C. Pichot, T. Delair, C. Viton and A. Domard, Langmuir, 2003, 19, 9896-9903.

38L. Mullins, Rubber Chem. Technol., 1969, 42, 339-362.

39J. Diani, B. Fayolle and P. Gilormini, Eur. Polym. J., 2009, 45, 601-612.

40I. Stevenson, L. David, C. Gauthier, L. Arambourg, J. Davenas and G. Vigier, Polymer, 2001, 42, 9287-9292.

41 R. E. Webber, C. Creton, H. R. Brown and J. P. Gong, Macromolecules, 2007, 40, 29192927.

42 G. R. Hamed and S. Hatfield, Rubber Chem. Technol., 1989, 62, 143-156.

43 F. Clément, L. Bokobza and L. Monnerie, Rubber Chem. Technol., 2001, 74, 847-870.

44 J.-Y. Sun, X. Zhao, W. R. K. Illeperuma, O. Chaudhuri, K. H. Oh, D. J. Mooney, J. J. Vlassak and Z. Suo, Nature, 2012, 489, 133-136.

45 J. p. Gong, Y. Katsuyama, T. Kurokawa and Y. Osada, Adv. Mater., 2003, 15, 1155-1158.

46S. Rose, A. Dizeux, T. Narita, D. Hourdet and A. Marcellan, Macromolecules, 2013, 46, 4095-4104.

47 W.-C. Lin, W. Fan, A. Marcellan, D. Hourdet and C. Creton, Macromolecules, 2010, 43, 2554-2563.

48 M. A. da Silva, F. Bode, I. Grillo and C. A. Dreiss, Biomacromolecules, 2015, 16, 14011409.

49B. Hammouda, F. Horkay and M. L. Becker, Macromolecules, 2005, 38, 2019-2021.

50 A. Osorio-Madrazo, L. David, S. Trombotto, J.-M. Lucas, C. Peniche-Covas and A. Domard, Carbohydr. Polym., 2011, 83, 1730-1739.

51 C. Pochat-Bohatier, V. Antoine, B. Denis, V. Laurent, D. Laurent and F. Catherine, J. Appl. Polym. Sci., 2013, 128, 2945-2953.

52E. Spruijt, F. A. M. Leermakers, R. Fokkink, R. Schweins, A. A. van Well, M. A. Cohen Stuart and J. van der Gucht, Macromolecules, 2013, 46, 4596-4605. 